Historic, archived document

Do not assume content reflects current scientific knowledge, policies, or practices. 



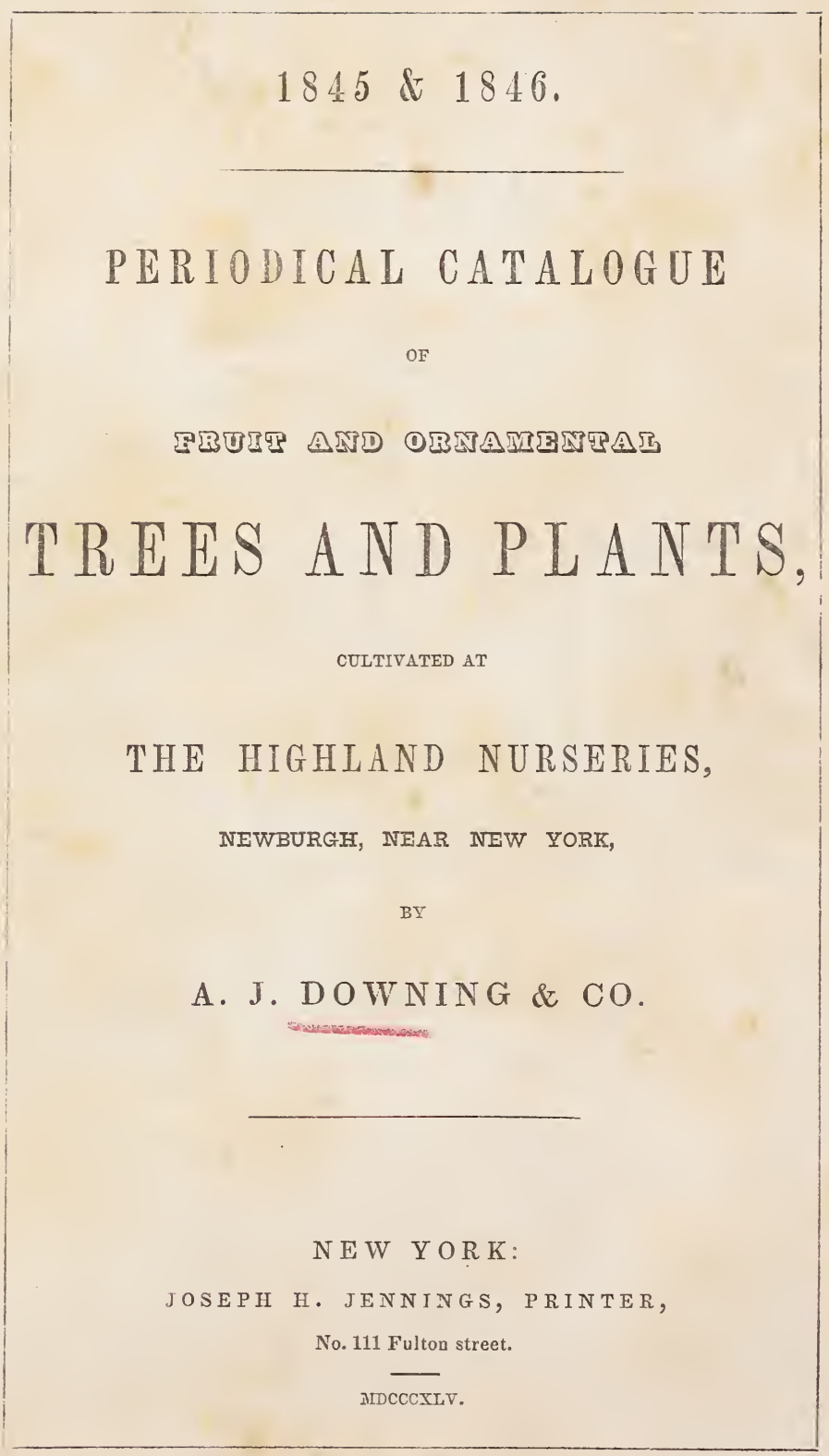





\section{ADVERTISEMENT.}

Since the last edition of our Catalogue, we have had the satisfaction of proving a large number of new fruits, in addition to those whose qualities have heretofore been carefully tested in the gardens here. The utmost care is exercised in propagating genuine sorts, and we have great pleasure in offering our present stock of trees to the public, as worthy of their confidence.

The nurseries here were commenced about forty years ago, and now contain over thirty acres of ground, exclusively devoted to the culture of trees, shrubs and plants. The soil and climate of the Hudson Highlands have rendered the success of the trees sent from here, a matter of notoriety in all parts of the Union.

Gentlemen who are little familiar with the subject, and who will favor us with the number of each species of fruit desired, as apples, pears, \&c., are assured that a selection made with the utmost care, and comprising the BEST, will be furnished by the proprietors. Persons wishing trees of extra size, should always send their orders in the autumn, as the largest nurseries are thinned by a whole season's sale.

The proper seasons for transplanting are October, November and December, in the autumn, and March and April, in the spring. The autumn is the most favorable time for the transmission of trees to the south and west, and our experience in packing trees for transportation, renders their success as certain at the distance of one or two thousand miles, as in our immediate neighborhood.

The bundles of trees or plants will be shipped from New York to any portion of North America or Europe ; and when it is desired, insurance will be effected-the purchaser being at the expense of the same.

The fluctuations in exchange, and the difficulty of obtaining remittances from some distant states, render it necessary for us to state, that all orders from those portions of the country must be accompanied by cash, or drafts on the city of New York, Boston, or Philadelphia, payable at sight, or within thirty days after the delivery of the trees. 
All letters on business, or making inquiries, must, to insure attention, be post paid. Persons living out of the usual routes of transportation, are requested to state the particular line, or conveyance, by which the bundles of trees are to be sent, and the amount of heary land carriage, and the trees will be packed accordingly. Orders by mail will receive the same attention, and the trees will be as carefully selected as when the person ordering them is present.

N. B.-Persons desiring a full and complete manual on the culture and propagation of fruit trees, directions for the care of orchards, modes of destroying insects, etc. etc., with descriptions and outline figures of all the finest fruits known in this country, are referred to Downing"s "FruTs ANd Frutt Trees or America," recently published, and for sale by booksellers in all the principal cities.

The pear blight, the "yellows" in the peach, and a very successful mode of pruning the latter tree, are treated of at length in this work. 


\section{DEPARTMENT OF FRUITS.}

\section{A P P L E .}

PRICE 25 CENTS EACH.

Cณㅗำ

SUMIIER A P PLES.

\begin{tabular}{|c|c|c|c|c|}
\hline NAME. & Size. & ity. & Season. & REMARKS. \\
\hline 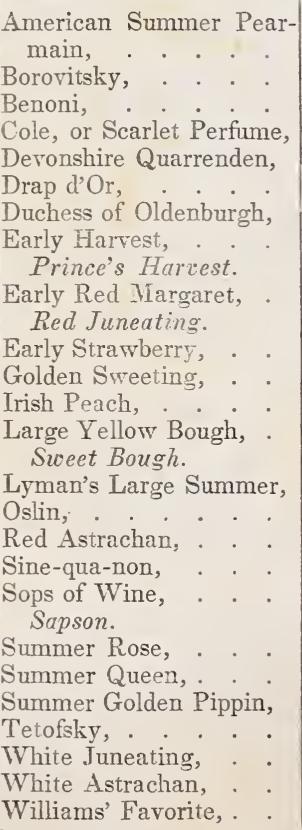 & $\begin{array}{l}\text { medium } \\
\text { medium } \\
\text { medium } \\
\text { large } \\
\text { medium } \\
\text { large } \\
\text { medium } \\
\text { medium } \\
\text { medium } \\
\text { medium } \\
\text { medium } \\
\text { medium } \\
\text { large } \\
\text { large } \\
\text { medium } \\
\text { large } \\
\text { medium } \\
\text { small } \\
\text { small } \\
\text { medium } \\
\text { small } \\
\text { medium } \\
\text { small } \\
\text { medium } \\
\text { large }\end{array}$ & $\begin{array}{l}1 \\
2 \\
1 \\
1 \\
1 \\
1 \\
2 \\
1\end{array}$ & $\begin{array}{l}\text { Aug. Sept. } \\
\text { Aug. } \\
\text { Aug. } \\
\text { Aug. } \\
\text { Aug. Sept. } \\
\text { Aug. Sept. } \\
\text { Aug. Sept. } \\
\text { July. } \\
\text { July. } \\
\text { July. Aug. } \\
\text { Aug. Sept. } \\
\text { Aug. } \\
\text { Aug. } \\
\text { Aug. Sept. } \\
\text { Aug. } \\
\text { July. Aug. } \\
\text { Aug. } \\
\text { Aug. Oct. } \\
\text { July. Aug. } \\
\text { Aug. } \\
\text { Aug. } \\
\text { Aug. } \\
\text { Aug. } \\
\text { Aug. } \\
\text { Aug. }\end{array}$ & $\begin{array}{l}\text { Handsome and excel- } \\
\text { lent. } \\
\text { A fine fruit. } \\
\text { A rich dessert fruit. } \\
\text { Large and excellent. } \\
\text { Superior in all re- } \\
\text { spects. } \\
\text { Very good. } \\
\text { Handsome \& sprightly } \\
\text { Productive and fine. } \\
\text { Large, and good. } \\
\text { A fine fruit. } \\
\text { Very beautiful,produc- } \\
\text { tive and good. } \\
\text { A nice dessert fruit. } \\
\text { Very good. } \\
\text { Productive and good. } \\
\text { Crisp and rich. } \\
\text { Inferior to Early Har- } \\
\text { vest. } \\
\text { Handsome \& excellent }\end{array}$ \\
\hline
\end{tabular}




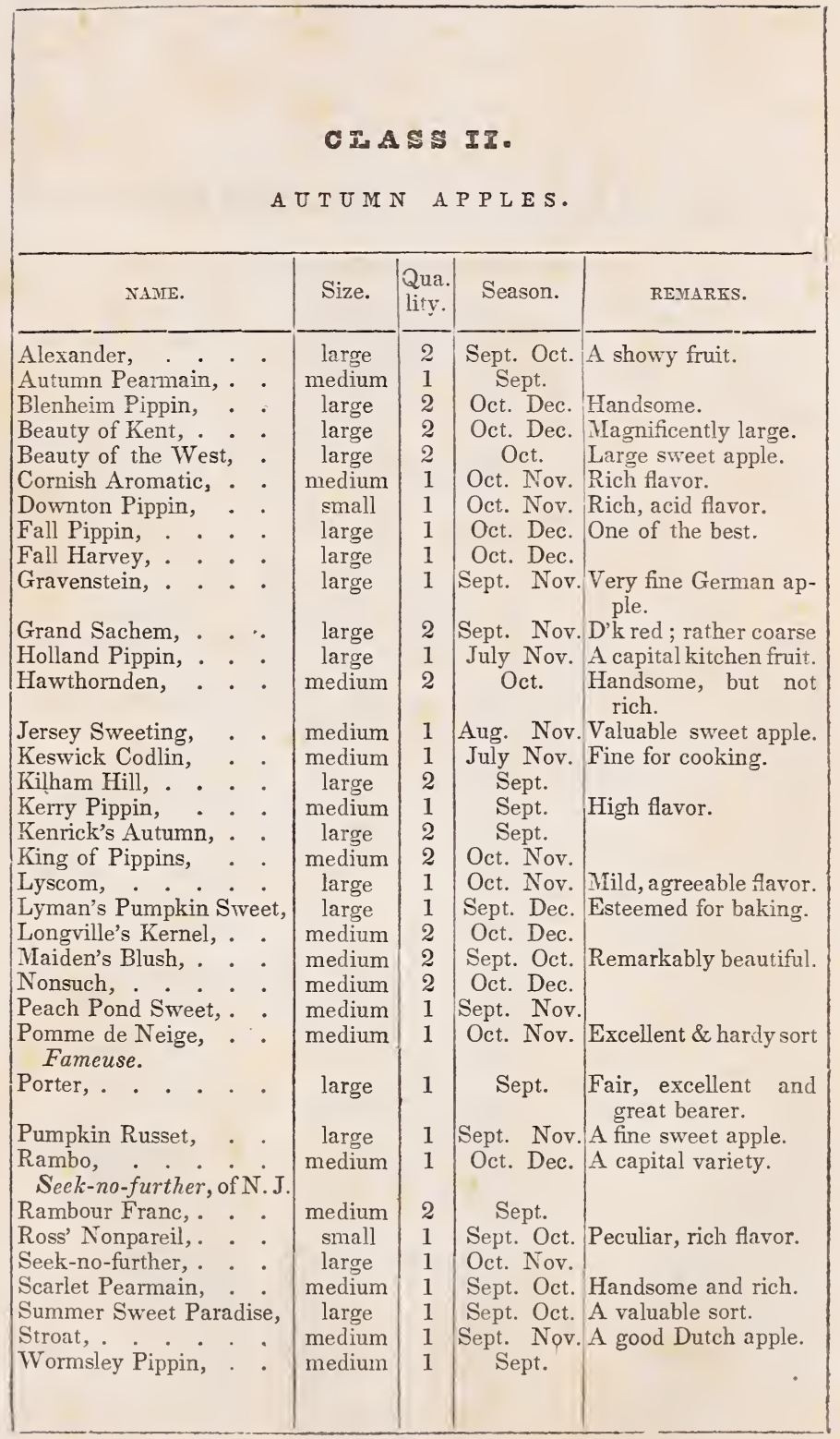




\begin{tabular}{|c|c|c|c|c|}
\hline \multicolumn{5}{|c|}{$\begin{array}{l}\text { CIA } \mathbf{A} \text { I II. } \\
\text { VINTER APPLES. }\end{array}$} \\
\hline NAME. & Size. & $\begin{array}{l}\text { Qua. } \\
\text { lity. }\end{array}$ & Season. & REMARKS. \\
\hline 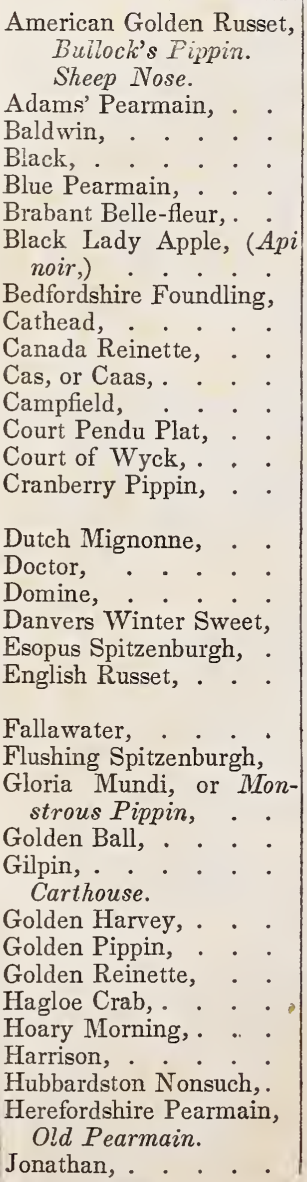 & \begin{tabular}{|l} 
small \\
medium \\
large \\
medium \\
large \\
large \\
small \\
large \\
large \\
large \\
large \\
medium \\
medium \\
small \\
large \\
large \\
medium \\
medium \\
medium \\
large \\
medium \\
large \\
large \\
large \\
medium \\
medium \\
small \\
small \\
small \\
medium \\
large \\
medium \\
large \\
medium \\
medium
\end{tabular} & $\begin{array}{l}2 \\
1 \\
2 \\
1 \\
1 \\
\\
2 \\
2 \\
2 \\
1 \\
1 \\
1 \\
1 \\
1 \\
2 \\
\\
1 \\
2 \\
2 \\
1 \\
1 \\
1 \\
1 \\
2 \\
\\
2 \\
1 \\
1 \\
1 \\
1 \\
1 \\
1 \\
2 \\
1 \\
1 \\
1\end{array}$ & \begin{tabular}{|c|} 
Nov. Feb. \\
Dec. April \\
Dec. April \\
Nov. Feb. \\
Oct. Feb. \\
Dec. April \\
Nov. Jan. \\
Oct. Feb. \\
Oct. Dec. \\
Nov. Mar. \\
Oct. Mar. \\
Oct. Dec. \\
Nov. Feb. \\
Oct. Feb. \\
Nov. Feb. \\
Oct. Mar. \\
Oct. Jan. \\
Nov. April \\
Dec. Mar. \\
Nov. Feb. \\
Jan. June \\
Nov. Feb. \\
Nov. Dec. \\
Sept. Jan. \\
Dec. Mar. \\
Feb. May \\
Oct. Dec. \\
Nov. Mar. \\
Nov. Jan. \\
Sept. \\
Oct. Dec. \\
Nov. Jan. \\
Oct. Jan. \\
Nov. Feb. \\
Oct. Mar.
\end{tabular} & $\begin{array}{l}\text { Unusually rich and } \\
\text { agreeable. } \\
\text { One of the finest of } \\
\text { winter apples, pro- } \\
\text { ductive, high-flavor- } \\
\text { ed, and keeps well. } \\
\text { Curious. } \\
\text { A good cooking apple. } \\
\text { Large and fine. } \\
\text { For cider only. } \\
\text { Beautiful dessert fruit. } \\
\text { High-flavored \& hardy } \\
\text { Handsome cooking ap- } \\
\text { ple. } \\
\text { Superb and excellent. } \\
\text { Agreeable,hardy; great } \\
\text { bearer. } \\
\text { Remarkably rich. } \\
\text { Great bearer; hardy } \\
\text { and good. } \\
\text { Productive and good. }\end{array}$ \\
\hline
\end{tabular}




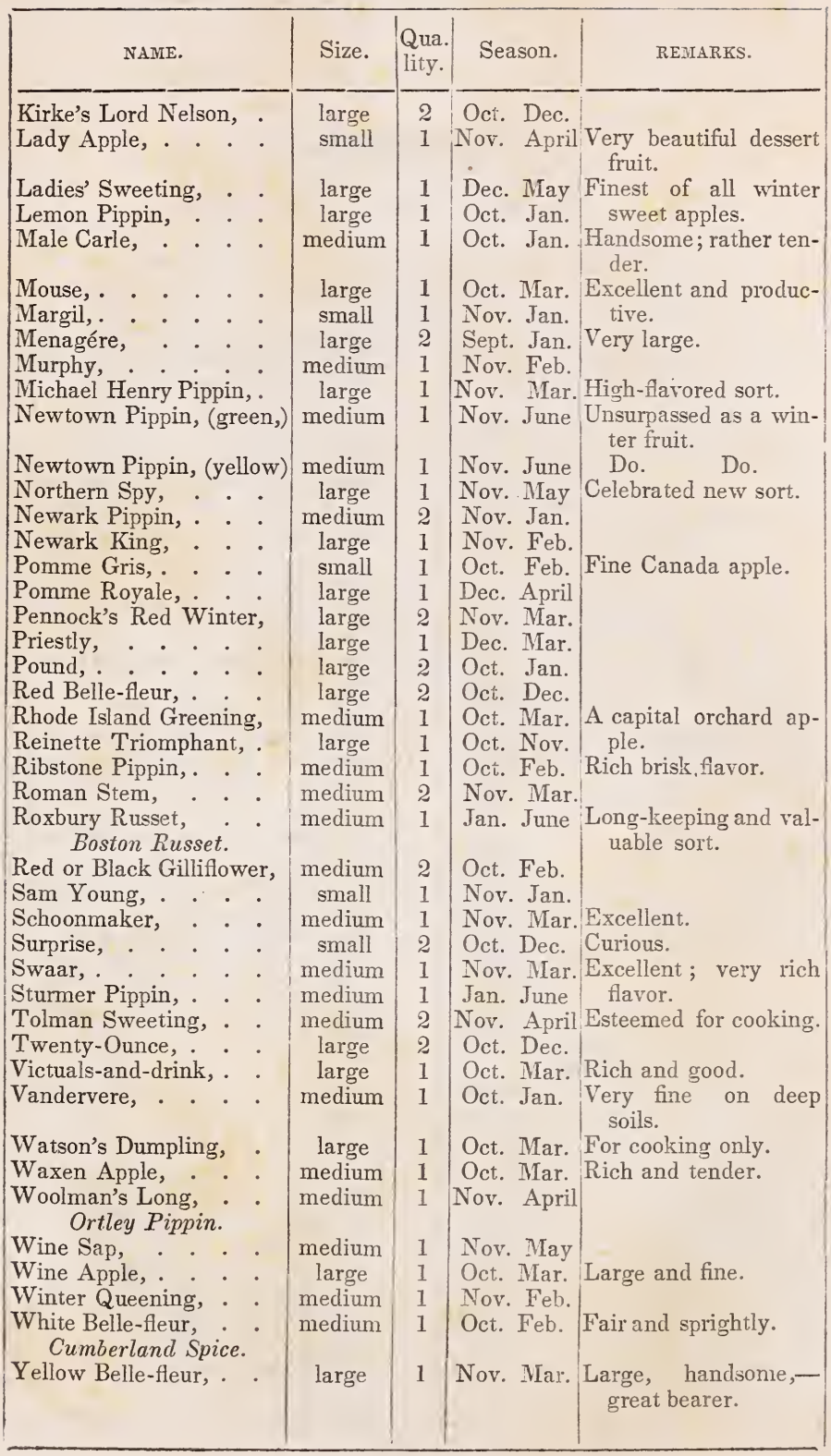


A P PLES.

\begin{tabular}{|l|c|c|c|c}
\hline \multicolumn{3}{|c|}{ APPLES F OR } & OR NA IIENT & OR PRESER V ING. \\
\hline \multicolumn{1}{|c|}{ NAME. } & Size. & $\begin{array}{l}\text { Qua. } \\
\text { lity. }\end{array}$ & Season. & REMARKs. \\
\hline $\begin{array}{l}\text { Chinese Double Flowering } \\
\text { Small Siberian Crab, } \\
\text { Large Siberian Crab, } \\
\text { Yellow or Amber Crab, }\end{array}$ & $\begin{array}{l}\text { small } \\
\text { small } \\
\text { small }\end{array}$ & $\begin{array}{l}\text { Sept. Oct. } \\
\text { Sept. Oct. } \\
\text { Sept. Oct. }\end{array}$ & $\begin{array}{l}\text { Theautiful blossoms. } \\
\text { small beautiful } \\
\text { for preserving. }\end{array}$ \\
\hline
\end{tabular}

\section{LIST OF APPLES,}

Received from various sources, and a portion of which have not yet been fully tested at this establishment. Small trees or grafts can be supplied of most of the varieties, and the whole are in course of propagation.

Arnold's Winter Sweeting.

Adam's Sweet.

Aunt Hannah.

Baldwin's Sweet.

Belden.

Bar.

Bevan.

Broadwell.

Budd's Summer Red Sweet.

Boxford.

Borden.

Conant's Red Winter.

Charlnowniski.

Cane.

Chandler.

Conway.

Cambunethean Pippin.

Detroit, (black.)

Dodge's Early Red.

Dartmouth Sweet.

Desivene Seedling.

Endicott Pippin.

Early and Late Sweet, (Earle's.)

Eustis.

Episcopal.

French's Sweet.

Fall Sweet.

Fall Bough.

Five-quartered Gilliflower.

Federal Pearmain.

Gardner's Pearmain.

Green Winter Sweet.

Garden Stripe.

Garden Royal.

Hartford Sweeting.

Holstein Sweeting.
Heart's Pippin.

Honey Greening.

Hooker.

Heath's Early Nonsuch.

Indian Rareripe.

Indian Prince, (Corses'.)

Jenning's Sweet.

Jewitt's Fine Red.

Knowle's Early Red.

King's Apple.

Kentish Pippin.

Lovett's Winter Sweet.

Laquier.

Leicester Sweet.

Lippincott.

Lady Healy's Nonsuch.

Little Greening.

Large English Codlin.

Morgan's Favorite.

Minister.

Mackey's Sweet.

Moore's Sweet.

Marquis.

Mank's Codlin.

Marigold.

Norwalk Sweet.

Norfolk Beanfir.

Orange Russet.

Pineapple Russet.

Pomwater Sweet.

Patten Apple.

President.

Pleasant Valley Pippin.

Putnam Harvey.

Putnam Russet.

Pear Apple. 


\begin{tabular}{|c|c|c|c|c|}
\hline \multicolumn{3}{|c|}{$\begin{array}{l}\text { Peach Apple, (Rivers'.) } \\
\text { Pineapple Russet. } \\
\text { Reinnette Van Mons. } \\
\text { Rapelje's Pippin. } \\
\text { Rymer. } \\
\text { Ramsdells Sweeting. } \\
\text { Sparking. } \\
\text { Sweet Pearmain. } \\
\text { Summer Spice. } \\
\text { Seaver Sweet. } \\
\text { Sweet Russet. } \\
\text { St. Lawrence, (Corses'.) } \\
\text { Soden Sweet. }\end{array}$} & \multicolumn{2}{|c|}{$\begin{array}{l}\text { Superb Sweet. } \\
\text { Sawyer Sweet. } \\
\text { Shippen's Russet. } \\
\text { Sprague. } \\
\text { Turn-of-the-lane. } \\
\text { Tift's Sweet. } \\
\text { Tewksbury Winter Blush. } \\
\text { Titus Pippin. } \\
\text { Winter Golden Sweet. } \\
\text { Wetherell's Red Sweet. } \\
\text { Winter Orange. } \\
\text { Wellington. } \\
\text { Wood's Greening. }\end{array}$} \\
\hline \multicolumn{5}{|c|}{$\begin{array}{c}\text { PE A R S } \\
\text { PRICE } 37 \frac{1}{2} \text { CENTS EACH: }\end{array}$} \\
\hline \multicolumn{5}{|c|}{$\begin{array}{l}\text { C I } \mathbf{A} \mathbf{S} \mathbf{I} . \\
\text { M NER PEARS. }\end{array}$} \\
\hline NAME. & Size. & $\begin{array}{l}\text { Qua. } \\
\text { lity. }\end{array}$ & Season. & REMARKS. \\
\hline 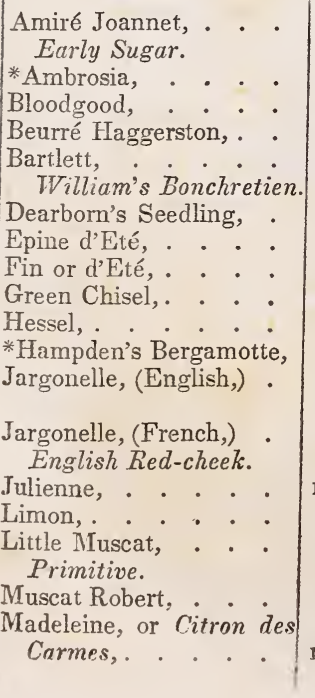 & \begin{tabular}{|} 
small \\
medium \\
medium \\
medium \\
large \\
medium \\
medium \\
medium \\
medium \\
small \\
large \\
large \\
large \\
medium \\
large \\
small \\
small \\
medium
\end{tabular} & $\begin{array}{l}2 \\
1 \\
1 \\
2 \\
1 \\
1 \\
2 \\
2 \\
2 \\
2 \\
2 \\
2 \\
2 \\
\\
2 \\
2 \\
2 \\
2\end{array}$ & \begin{tabular}{|c|} 
July \\
Aug. \\
July \\
Aug. \\
Aug. Sept. \\
Aug. \\
Aug. Sept. \\
Aug. \\
Aug. \\
Aug. Sept. \\
Aug. \\
July Aug. \\
July Aug. \\
Aug. \\
Aug. \\
July \\
July
\end{tabular} & $\begin{array}{l}\text { The finest early pear. } \\
\text { t. Large, productive and } \\
\text { excellent. } \\
\text { Delicious; very hardy, } \\
\text { and great bearer. } \\
\text { t. Great bearer, \& hardy. } \\
\text { An orchard pear, } \\
\text { great bearer. } \\
\text { Handsome, but dry. } \\
\text { Regular bearer; often } \\
\text { very excellent. } \\
\text { Earliness its chief merit }\end{array}$ \\
\hline
\end{tabular}


PEARS.

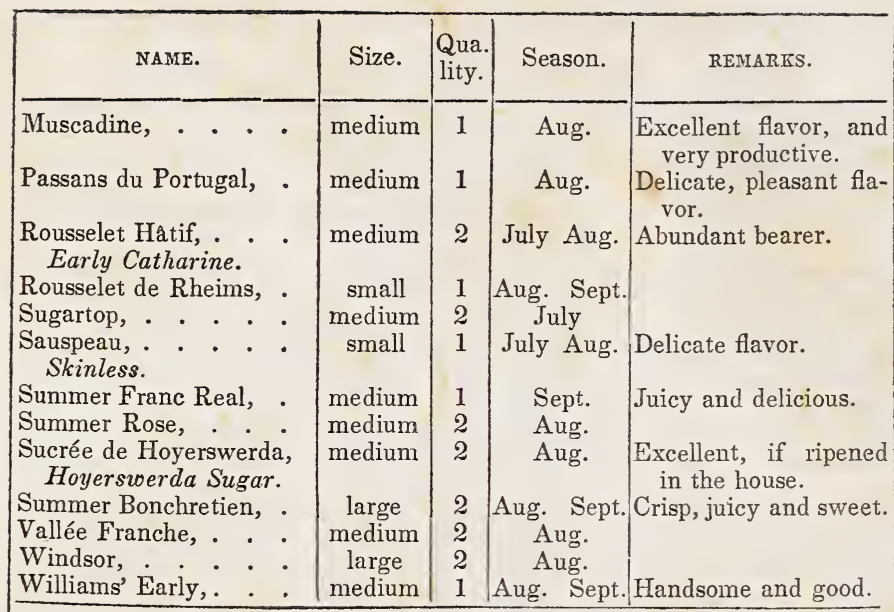

\section{I A I II.}

A UTUMN PEARS.

\begin{tabular}{|c|c|c|c|c|}
\hline NAME. & Size. & $\begin{array}{l}\text { Qua. } \\
\text { lity. }\end{array}$ & Season. & REMARKS. \\
\hline 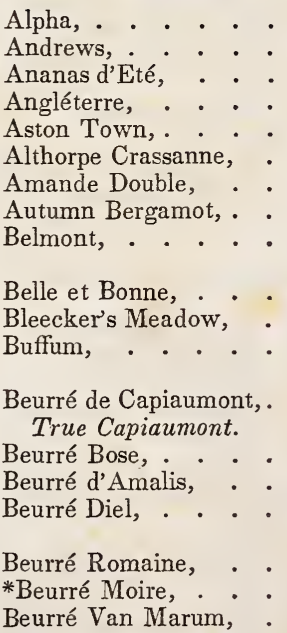 & $\begin{array}{l}\text { medium } \\
\text { large } \\
\text { medium } \\
\text { medium } \\
\text { small } \\
\text { medium } \\
\text { medium } \\
\text { small } \\
\text { medium }\end{array}$ & $\begin{array}{l}2 \\
1 \\
1 \\
2 \\
2 \\
1 \\
2 \\
2 \\
1\end{array}$ & $\begin{array}{c}\text { Oct. } \\
\text { Sept. } \\
\text { Sept. Oct. } \\
\text { Sept. } \\
\text { Sept. } \\
\text { Oct. } \\
\text { Sept. } \\
\text { Sept. } \\
\text { Oct. } \\
\text { Sept. } \\
\text { Oct. Nov. } \\
\text { Sept. } \\
\text { Sept. Oct. } \\
\text { Sept. Oct. } \\
\text { Sept. } \\
\text { Sept. Dec. }\end{array}$ & $\begin{array}{l}\text { Melting. } \\
\text { Great bearer. } \\
\text { Melting, peculiar fla- } \\
\text { vor. } \\
\text { Very excellent stewing } \\
\text { pear. } \\
\text { Showy and large. } \\
\text { Great bearer ; hand- } \\
\text { some and very good. } \\
\text { Good orchard pear. } \\
\text { Very excellent. } \\
\text { Large, handsome, and } \\
\text { good. } \\
\text { Fair, juicy and good. }\end{array}$ \\
\hline
\end{tabular}




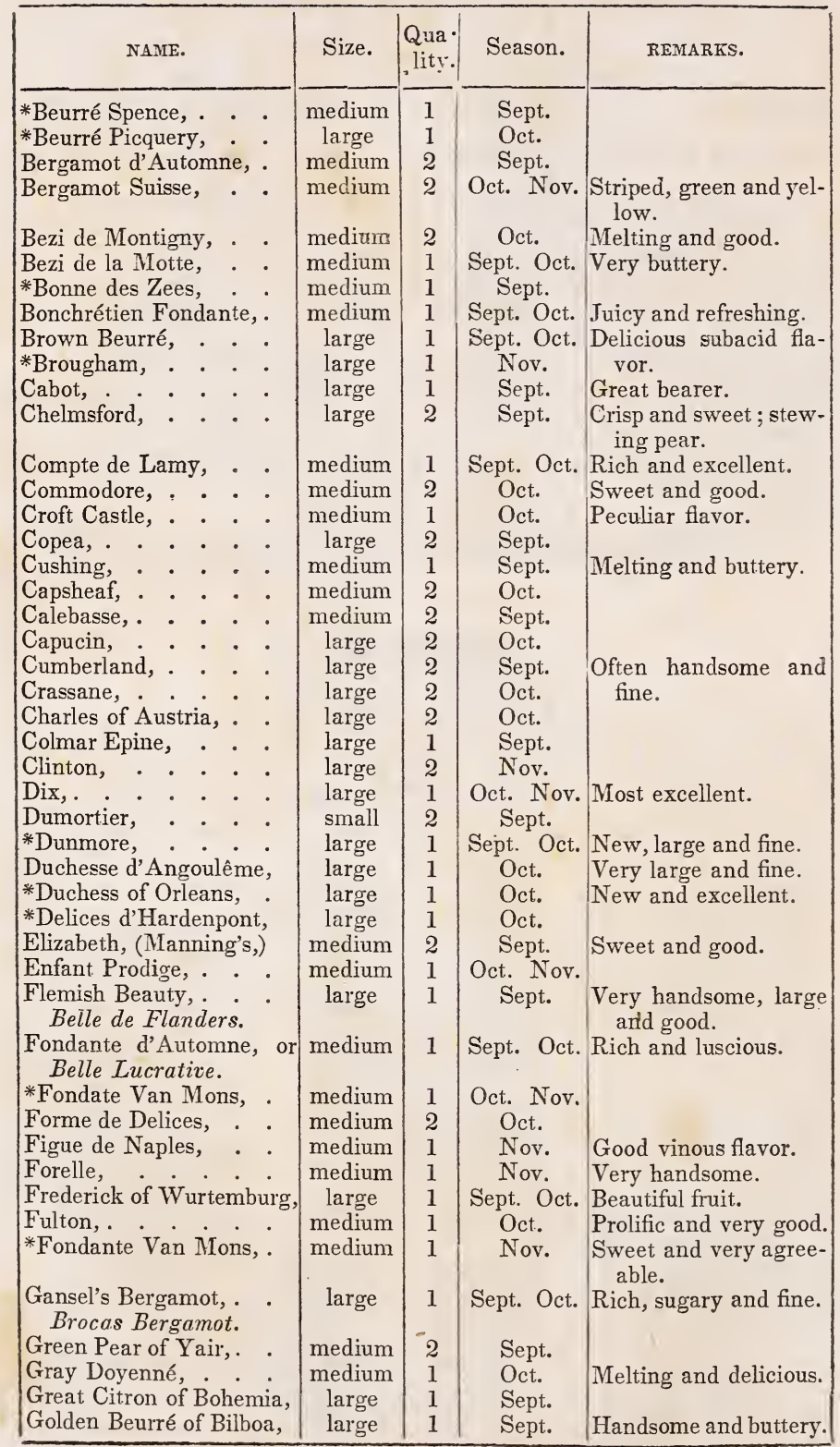


PEARS.

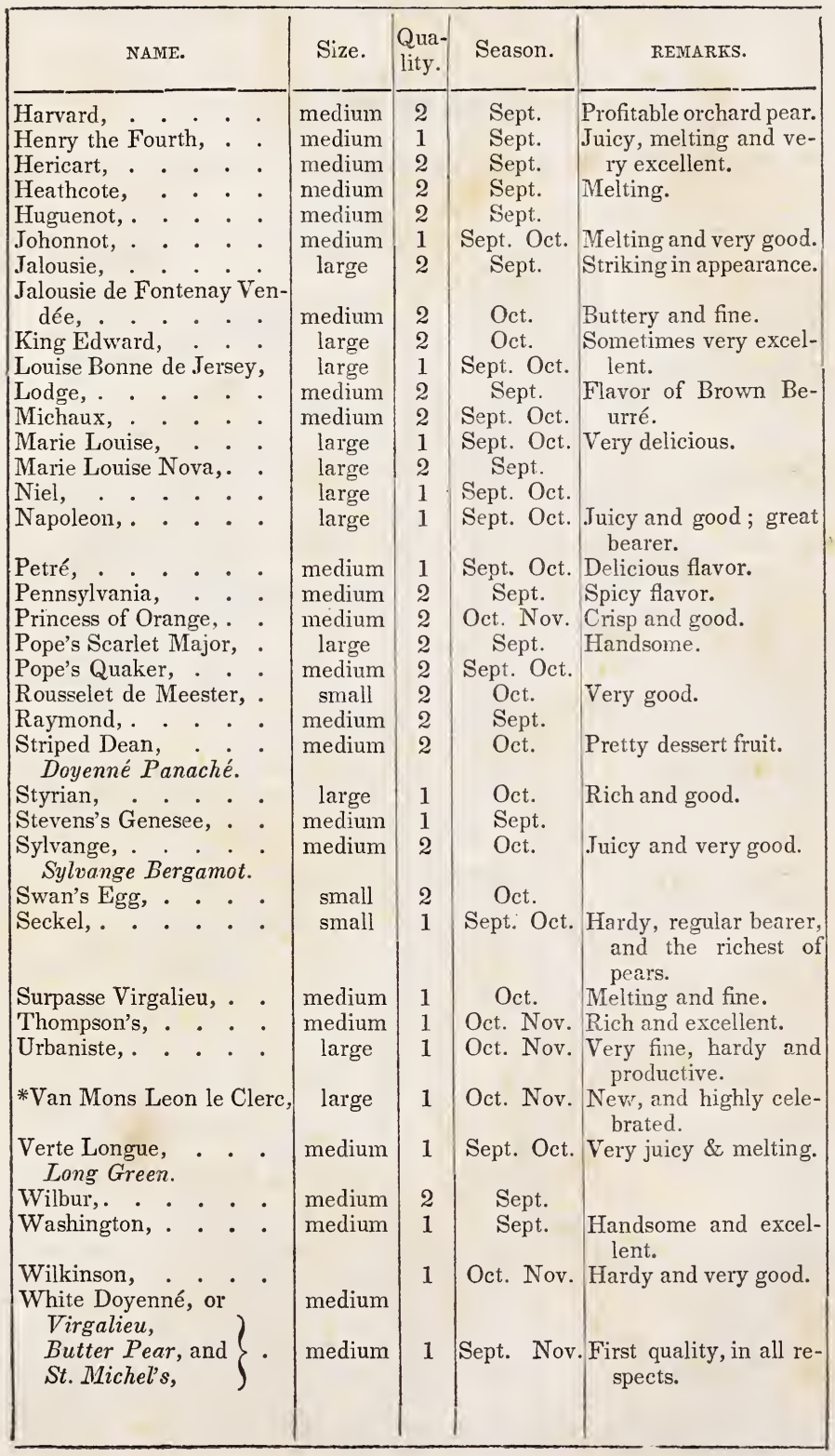




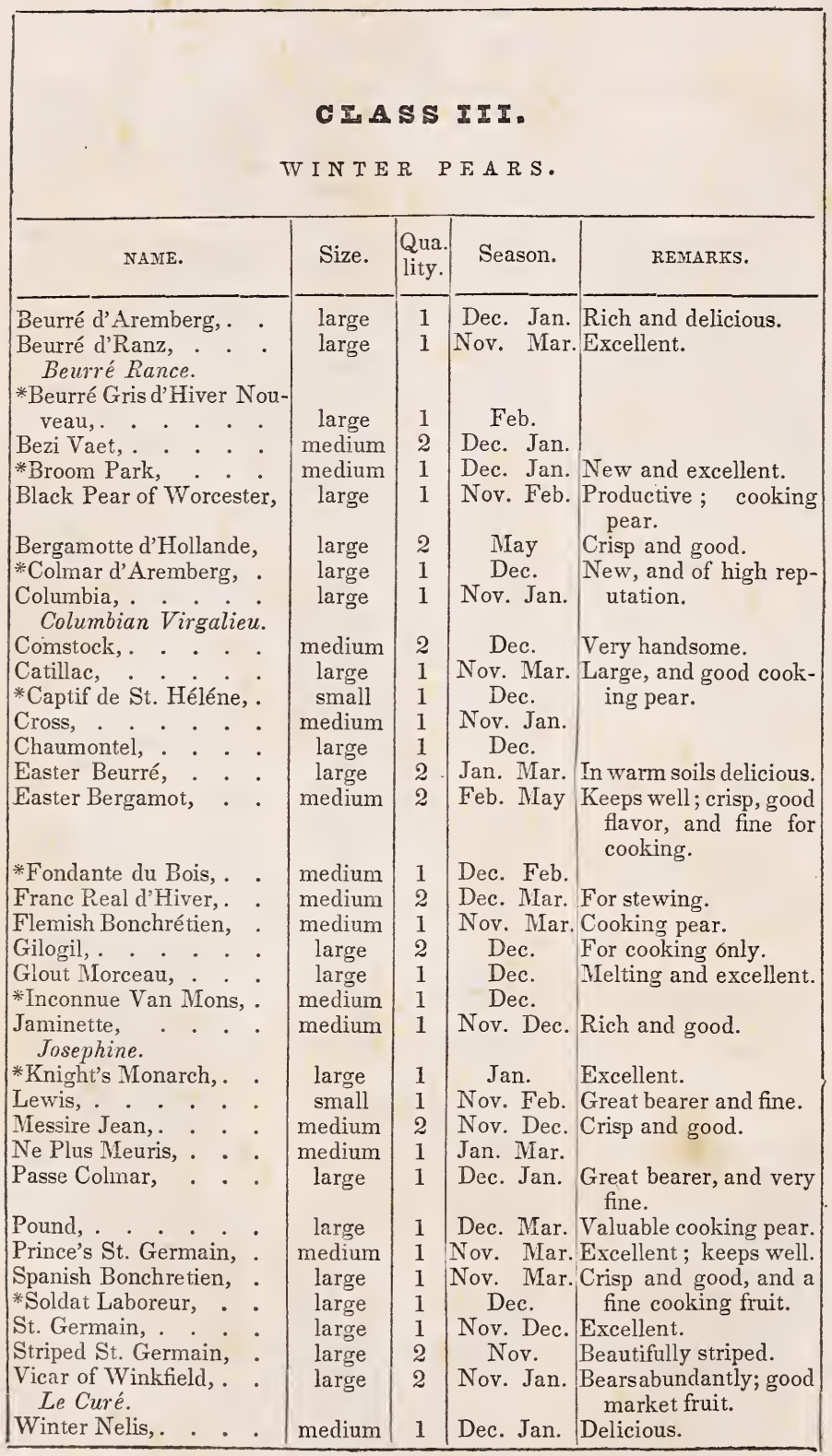




\section{LIST OF PEARS,}

In course of propagation, of which small trees or grafts only can be supplied the present season.

\begin{tabular}{l|l}
\hline Ananas. & *Gendesheim. \\
Autumn Superb. & Henkit. \\
Angora. & *Jean de Witte. \\
*Beurré de Beaumont. & Louis of Bologna. \\
Beurré Duval. & McLaughlin. \\
*Beurré Colmar. & *Mollett's Guernsey Beurré. \\
Beurré Preble. & *Mansuette. \\
*Beurré Paternoster. & Nouvelle Mabille. \\
Beurré Van Mons. & Madame Vert. \\
Brown Favorite. & Queen of the Lor Countries. \\
Bishop's Thumb. & Reine Caroline. \\
*Colmar Neill. & Reine des Poires. \\
*De Louvain. & Rousselet Panaché. \\
*Duchesse de Mars. & Summer St. Germain. \\
*Doyenné d'Hiver Nouveau. & Van Assene. \\
*Dundas. & Winter Orange. \\
*Elton. & Winter Virgalieu. \\
*Jalvie. & Whitfield. \\
Gil. & *Tilhelmina. \\
\hline
\end{tabular}

\section{PLUMS.}

PRICE 50 CENTS EACH.

प1 3 Some rare sorts, marked *, are $75 \mathrm{cts}$. each.

\begin{tabular}{|c|c|c|c|c|}
\hline NAME. & Size. & Color. & Season. & REMARKS. \\
\hline $\begin{array}{l}\text { Apricot, } \\
\text { Abricotée Rouge, . } \\
\text { Red Apricot. } \\
\text { Autumn Gage, . . } \\
\text { American Wheat, . } \\
\text { Angola, . . . } \\
\text { Byfield, . . . } \\
\text { Bingham, . . . } \\
\text { Bleecker's Gage, . } \\
\text { Blue Gage, . · } \\
\text { Azure Hative. } \\
\text { *Blue Imperatrice, } \\
\text { Blue Perdrigon, } \\
\text { Brevoort's Purple, . } \\
\text { Columbia, . }\end{array}$ & 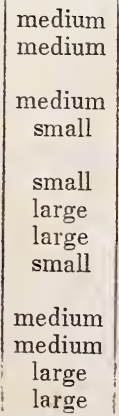 & $\begin{array}{l}\text { yellow } \\
\text { red } \\
\text { yellow } \\
\text { blue } \\
\text { yellow } \\
\text { yellow } \\
\text { yellow } \\
\text { blue } \\
\text { purple } \\
\text { purple } \\
\text { purple } \\
\text { reddish }\end{array}$ & $\begin{array}{l}\text { m. Aug. } \\
\text { Aug. } \\
\text { e. Sept. } \\
\text { Sept. } \\
\text { Aug. } \\
\text { Sept. } \\
\text { Aug. } \\
\text { Aug. } \\
\text { Sept. Oct. } \\
\text { Aug. } \\
\text { Sept. } \\
\text { Sept. }\end{array}$ & $\begin{array}{l}\text { Large and excellent. } \\
\text { Very hardy and valua- } \\
\text { ble. } \\
\text { Late and fine. } \\
\text { Very large and fine. }\end{array}$ \\
\hline
\end{tabular}




\begin{tabular}{|c|c|c|c|c|}
\hline NAME. & Size. & Color. & Season. & REMARKS. \\
\hline & & & & Excellent. \\
\hline & & & Oct. Nov. & Valuable late sort. \\
\hline $\begin{array}{l}\text { Cooper's Large Red, } \\
\text { La Délicieuse. }\end{array}$ & large & reddish & e. Sept. & Liable to rot. \\
\hline Corse's Admiral, . & medium & reddish & & \\
\hline Corse's Nota Bene, & large & brow & Sept. & Excellent; productive. \\
\hline Cruger's Scarlet, . & & & & $\begin{array}{l}\text { Very hardy;-great } \\
\text { bearer. }\end{array}$ \\
\hline $\begin{array}{l}\text { Cherry, } \\
\text { Early Scarlet. }\end{array}$ & small & red & July & Pretty and very early. \\
\hline Cheston, . . . & small & purple & July & \\
\hline yer's Victoria, & lar & & & \\
\hline s Yellow Gage, & med & & & Excellent. \\
\hline $\begin{array}{l}\text { Drap d'Or, } \cdot \text { - } \\
\text { Downton Imperatrice, }\end{array}$ & $\begin{array}{l}\text { medium } \\
\text { medium }\end{array}$ & & $\begin{array}{l}\text { Aug. } \\
\text { Sept. }\end{array}$ & $\begin{array}{l}\text { Fine. } \\
\text { Finetient. }\end{array}$ \\
\hline Domine Dull, . . & medium & & & $\begin{array}{l}\text { Hangs long; good fla- } \\
\text { vor. }\end{array}$ \\
\hline Diamond, · · & large & purple & Sept. & $\begin{array}{l}\text { Very large, but only } \\
\text { for cooking. }\end{array}$ \\
\hline $\begin{array}{c}\text { Duane's French Pur- } \\
\text { ple,. . . . . . }\end{array}$ & large & & Aug. & Handson \\
\hline $\begin{array}{l}\text { Diaprée Rouge, } \\
\text { IIimm's. }\end{array}$ & large & & Aug. & Most excellent. \\
\hline Damson,. . . & small & purple & ept. & For preserving. \\
\hline $\begin{array}{l}\text { Elfrey, } \\
\text { Emerald Drop, }\end{array}$ & edium & & Sept. & \\
\hline $\begin{array}{l}\text { Early Orleans, } \\
\text { Early Monsieur. }\end{array}$ & $\begin{array}{l}\text { medium } \\
\text { medium }\end{array}$ & & $\begin{array}{l}\text { Aug. } \\
\text { Aug. }\end{array}$ & $\begin{array}{l}\text { Fine flavor. } \\
\text { Very good. }\end{array}$ \\
\hline $\begin{array}{l}\text { Frost Gage, . . } \\
\text { Ghiston's Early, }\end{array}$ & $\begin{array}{l}\text { medium } \\
\text { large }\end{array}$ & & $\begin{array}{l}\text { Oct. } \\
\text { Aug. }\end{array}$ & $\begin{array}{l}\text { Productive and excel- } \\
\text { lent. }\end{array}$ \\
\hline $\begin{array}{l}\text { Green Gage, } \\
\text { Bruyn Gage. }\end{array}$ & medium & & & Very excellent. \\
\hline Goliath, . · & large & & & \\
\hline 's Superb, & large & & & $\begin{array}{l}\text { A superb fruit, in all } \\
\text { respects. }\end{array}$ \\
\hline $\begin{array}{l}\text { Howell's Early, } \\
\text { *Ickworth Impera- }\end{array}$ & & reddish & July & \\
\hline & medium & purple & Oct. & \\
\hline Imperial Ottoman, & medium & $\begin{array}{l}\text { green } \\
\text { purple }\end{array}$ & $\begin{array}{l}\text { July } \\
\text { Sept. }\end{array}$ & \\
\hline $\begin{array}{l}\text { Isabella, . . . } \\
\text { Jefferson, }\end{array}$ & $\begin{array}{l}\text { large } \\
\text { large }\end{array}$ & & & \\
\hline Jaune Hâtive, . & $\begin{array}{l}\text { large } \\
\text { small }\end{array}$ & & $\begin{array}{l}\text { Sel } \\
\text { Jul }\end{array}$ & eautiful and fine. \\
\hline Kirke's, ·; $\dot{\text { Frarte }}$ & large & purple & Sept. & \\
\hline $\begin{array}{l}\text { Lawrence's Favorite, } \\
\text { Lafayette, · . } \\
\text { *Large Green Drying, }\end{array}$ & $\begin{array}{l}\text { large } \\
\text { medium }\end{array}$ & $\begin{array}{l}\text { green } \\
\text { green }\end{array}$ & $\begin{array}{l}\text { Aug. } \\
\text { Aug. }\end{array}$ & Large and fine. \\
\hline $\begin{array}{l}\text { (Knight's,) } \\
\text { Lombard, } \\
\text { Bleecker's Scarlet. }\end{array}$ & $\begin{array}{l}\text { large } \\
\text { medium }\end{array}$ & $\begin{array}{l}\text { green } \\
\text { red }\end{array}$ & $\begin{array}{l}\text { Sept. } \\
\text { Aug. }\end{array}$ & $\begin{array}{l}\text { New and rich. } \\
\text { Productive in every } \\
\text { soil. }\end{array}$ \\
\hline $\begin{array}{l}\text { Long Scarlet, } \\
\text { Lucombe's Nonsuch, } \\
\text { Manning's Yellow, }\end{array}$ & $\begin{array}{l}\text { medium } \\
\text { large }\end{array}$ & $\begin{array}{l}\text { red } \\
\text { green }\end{array}$ & $\begin{array}{l}\text { Sept. } \\
\text { Aug. }\end{array}$ & Fine for jellies. \\
\hline
\end{tabular}


PLUMS.

\begin{tabular}{|c|c|c|c|c|}
\hline NAME. & Size. & Color. & Season. & REIIARES. \\
\hline 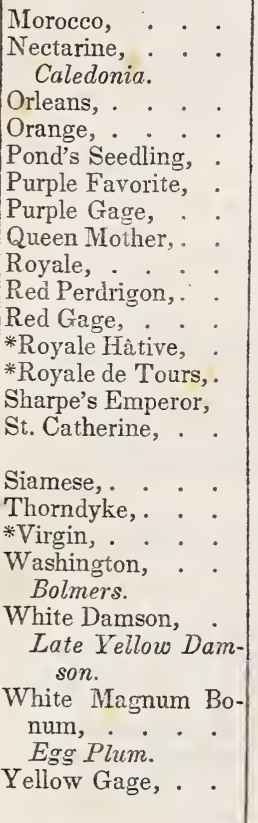 & \begin{tabular}{|} 
medium \\
large \\
medium \\
large \\
medium \\
medium \\
medium \\
small \\
medium \\
medium \\
medium \\
medium \\
large \\
large \\
medium \\
medium \\
medium \\
medium \\
large \\
small
\end{tabular} & $\begin{array}{l}\text { purple } \\
\text { purple } \\
\text { purple } \\
\text { yellow } \\
\text { purple } \\
\text { purple } \\
\text { purple } \\
\text { red } \\
\text { purple } \\
\text { red } \\
\text { red } \\
\text { purple } \\
\text { red } \\
\text { red } \\
\text { yellow } \\
\text { yellow } \\
\text { green } \\
\text { purple } \\
\text { yellow }\end{array}$ & $\begin{array}{c}\text { July } \\
\text { Aug. } \\
\text { Aug. } \\
\text { Sept. } \\
\text { Aug. } \\
\text { Sept. } \\
\text { Sept. } \\
\text { Sept. } \\
\text { Sept. } \\
\text { Sept. } \\
\text { Aug. } \\
\text { July } \\
\text { July } \\
\text { Sept. } \\
\text { Sept. Oct. } \\
\text { Sept. } \\
\text { Aug. } \\
\text { Sept. } \\
\text { Aug. } \\
\text { Sept. Oct. }\end{array}$ & $\begin{array}{l}\text { Very good. } \\
\text { Large and handsome. } \\
\text { Good bearer. } \\
\text { Very large. } \\
\text { Delicious flavor. } \\
\text { Excellent. } \\
\text { Rich; hangs long. } \\
\text { A fine late plum. } \\
\text { Luscious; great bearer } \\
\\
\text { Handsome. } \\
\text { Productive and excel- } \\
\text { lent. } \\
\text { Curious; fruit in pairs. }\end{array}$ \\
\hline
\end{tabular}

\section{LIST OF PLUMS,}

In course of propagation, of which only small trees can yet be supplied.

Buel's Favorite.

Blue Perdrigon.

Denniston's Albany Beauty. Superb. Red.

Fotheringham.

Fonday.
Mirabelle.

Peoly's Early Blue.

Red Magnum Bonum.

Rivers's Early, No. 1.

Rivers's Early, No.2.

St. Martin's Quetsche.

Thomas. 


\section{PEACHES.}

PRICE 25 CENTS EACH.

(C) denotes such as are clingstones.

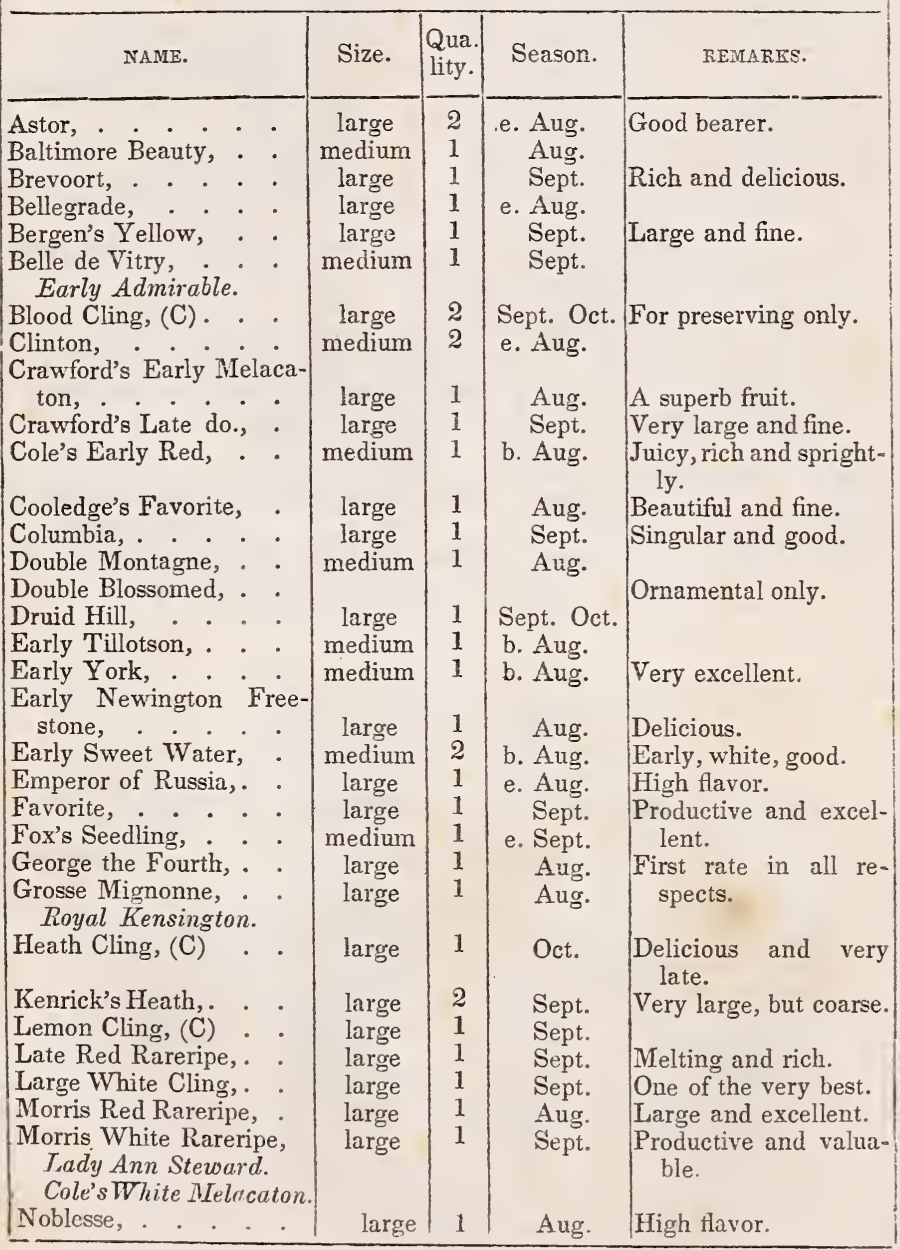




\begin{tabular}{|c|c|c|c|c|}
\hline NAME. & Size. & $\begin{array}{c}\text { Qua. } \\
\text { lity. }\end{array}$ & Season. & REMARKS. \\
\hline 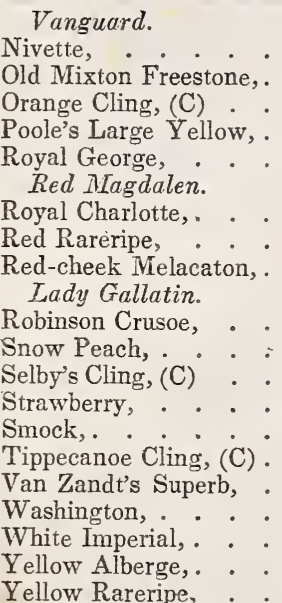 & $\begin{array}{c}\text { large } \\
\text { large } \\
\text { large } \\
\text { large } \\
\text { large } \\
\text { large } \\
\text { large } \\
\text { large } \\
\text { large } \\
\text { large } \\
\text { large } \\
\text { medium } \\
\text { large } \\
\text { large } \\
\text { large } \\
\text { large } \\
\text { medium } \\
\text { medium } \\
\text { large }\end{array}$ & $\begin{array}{l}1 \\
1 \\
1 \\
1 \\
1 \\
1 \\
1 \\
1 \\
1 \\
\\
2 \\
1 \\
1 \\
1 \\
1 \\
1 \\
1 \\
1 \\
1 \\
2 \\
1\end{array}$ & $\begin{array}{l}\text { Sept. } \\
\text { Sept. } \\
\text { Sept. } \\
\text { Oct. } \\
\text { e. Aug. } \\
\text { Sept. } \\
\text { Aug. } \\
\text { Sept. } \\
\text { Sept. } \\
\text { Sept. } \\
\text { Sept. } \\
\text { Aug. } \\
\text { Oct. } \\
\text { Sept. } \\
\text { Sept. } \\
\text { Sept. } \\
\text { e. Aug. } \\
\text { Sept. } \\
\text { e. Aug. }\end{array}$ & $\begin{array}{l}\text { Very fine flavor. } \\
\text { Very fine. } \\
\text { Large and productive. } \\
\text { Productive and good. } \\
\text { Beautiful and good. } \\
\text { Earlier than Large } \\
\text { White Cling. } \\
\text { Large and handsome. } \\
\text { Handsome. }\end{array}$ \\
\hline
\end{tabular}

\section{LIST OF PEACHES,}

In course of propagation, of which trees will not be for sale till the autumn of 1846 .

\begin{tabular}{|c|c|c|c|c|}
\hline \multicolumn{3}{|c|}{$\begin{array}{l}\text { Acton Scott. } \\
\text { Barrington. } \\
\text { Chancellor. } \\
\text { Hardy Gallande. } \\
\text { Incomparable Cling, (C.) } \\
\text { La Grange. } \\
\text { Large Melting. } \\
\text { Late Admirable. }\end{array}$} & \multicolumn{2}{|c|}{$\begin{array}{l}\text { Morrisania Pound. } \\
\text { Pavie Admirable. } \\
\text { Malta. } \\
\text { Madeleine de Courson. } \\
\text { Red Admirable. } \\
\text { Swalsh. } \\
\text { Sulhampstead. }\end{array}$} \\
\hline \multicolumn{5}{|c|}{$\begin{array}{c}\text { C ERR I E. } \\
\text { PRICE } 40 \text { CTS. EACH. } \\
\text { C } \mathbf{A} \mathbf{A} \mathbf{I} \text {. } \\
\text { HEART CHERRIES. }\end{array}$} \\
\hline NANE. & Size. & Color. & Season. & REMARKS. \\
\hline $\begin{array}{l}\text { American Amber, . } \\
\text { Bloodgood's Honey. } \\
\text { Amber Gean, . . } \\
\text { Black Heart, . . } \\
\text { Black Eagle, . }\end{array}$ & $\begin{array}{l}\text { medium } \\
\text { small } \\
\text { medium } \\
\text { large }\end{array}$ & $\begin{array}{l}\text { lt. red } \\
\text { amber } \\
\text { black } \\
\text { black }\end{array}$ & $\begin{array}{l}\text { e. Juise } \\
\text { July } \\
\text { e. June } \\
\text { b. July }\end{array}$ & $\begin{array}{l}\text { Productive ;-medium } \\
\text { quality. } \\
\text { Pretty; delicate flavor } \\
\text { Great bearer. } \\
\text { Richest black cherry. }\end{array}$ \\
\hline
\end{tabular}




\begin{tabular}{|c|c|c|c|c|}
\hline NAME. & Size. & Color. & Season. & REMARKS. \\
\hline 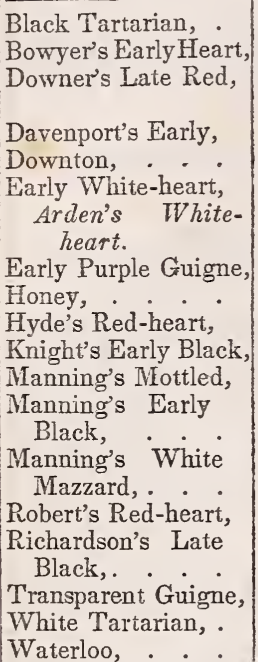 & $\begin{array}{c}\text { medium } \\
\text { small } \\
\text { medium } \\
\text { large } \\
\text { medium } \\
\text { medium } \\
\text { small } \\
\text { large } \\
\text { small } \\
\text { small } \\
\text { medium } \\
\text { large }\end{array}$ & $\begin{array}{l}\text { black } \\
\text { am. red } \\
\text { lt. red } \\
\text { black } \\
\text { amber } \\
\text { black } \\
\text { amber } \\
\text { red } \\
\text { black } \\
\text { amber } \\
\text { amber } \\
\text { purple }\end{array}$ & $\begin{array}{l}\text { b. June } \\
\text { July } \\
\text { e. June } \\
\text { June } \\
\text { e. June } \\
\text { b. June } \\
\text { July } \\
\text { e. June }\end{array}$ & $\begin{array}{l}\text { Most excellent and } \\
\text { very large. } \\
\text { Sweet, delicious and } \\
\text { late. } \\
\text { An early black-heart. } \\
\text { Fine flavor. } \\
\text { One of the earliest } \\
\text { good cherries. } \\
\text { New, fine, very early. }\end{array}$ \\
\hline
\end{tabular}

CI $\mathrm{A}$ S 1 I.

BIGARR A U CHERRIES。

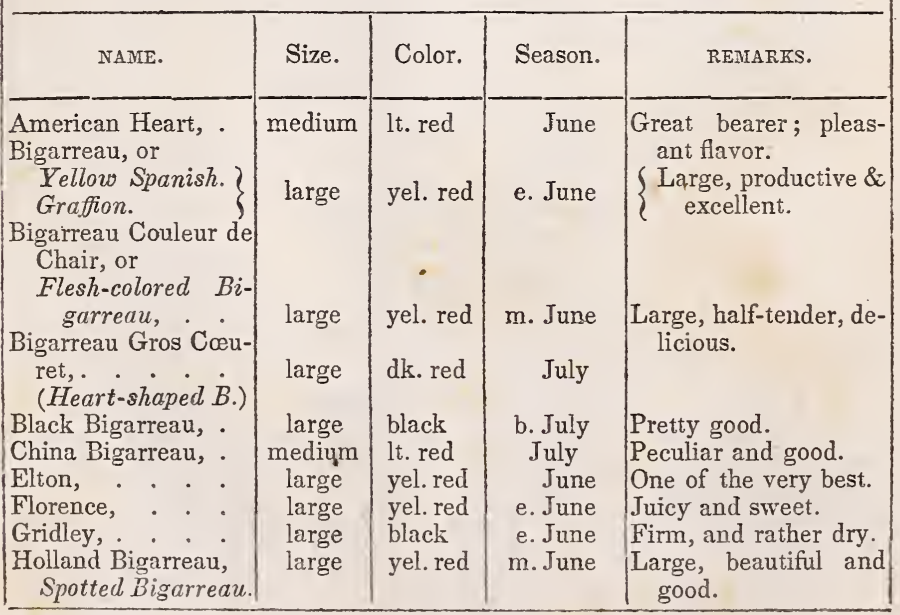




\begin{tabular}{|c|c|c|c|c|}
\hline NAME. & Size. & Color. & Season. & reMaRLS. \\
\hline $\begin{array}{l}\text { Madison Bigarreau, } \\
\text { Napoleon Bigarreau, } \\
\text { Tradescant's Black, } \\
\text { Elkhorn. } \\
\text { White Bigarreau, . } \\
\text { White Ox-heart. }\end{array}$ & $\begin{array}{l}\text { medium } \\
\text { large } \\
\text { large } \\
\text { large }\end{array}$ & $\begin{array}{l}\text { yel. red } \\
\text { yel. red } \\
\text { black } \\
\text { yel. red }\end{array}$ & $\begin{array}{l}\text { e. June } \\
\text { e. June } \\
\text { July } \\
\text { e. June }\end{array}$ & $\begin{array}{l}\text { Pleasant flavor. } \\
\text { Very large. } \\
\text { Very firm, late and } \\
\text { rich. } \\
\text { Excellent. }\end{array}$ \\
\hline
\end{tabular}

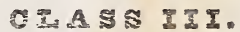

DUKE, AND MORELLO CHERRIES.

\begin{tabular}{|c|c|c|c|c|}
\hline NAME. & Size. & Color. & Season. & REMAKKS. \\
\hline 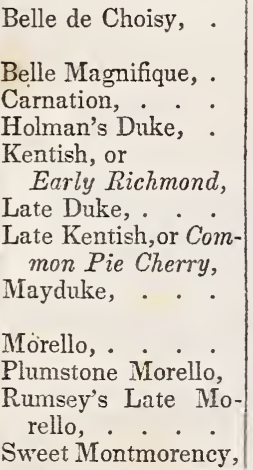 & $\begin{array}{l}\text { medium } \\
\text { large } \\
\text { medium } \\
\text { medium } \\
\text { large } \\
\text { medium } \\
\text { medium }\end{array}$ & $\begin{array}{l}\text { red } \\
\text { red } \\
\text { red } \\
\text { red } \\
\text { lt. red } \\
\text { red } \\
\text { red }\end{array}$ & $\begin{array}{l}\text { e. June } \\
\text { July } \\
\text { July } \\
\text { e. June } \\
\text { b. June } \\
\text { July } \\
\text { July } \\
\text { b. June }\end{array}$ & $\begin{array}{l}\text { Pellucid, sweet and de- } \\
\text { licious. } \\
\text { Late; for preserving. } \\
\text { Pleasant subacid flavor } \\
\text { Earliest cooking cherry } \\
\text { Very late and good. } \\
\text { Valuable old sort. } \\
\text { Most valuable in all re- } \\
\text { spects. } \\
\text { For cooking. } \\
\text { Largest and best Mo- } \\
\text { rello. } \\
\text { Peculiar ; very late. } \\
\text { Latest sweet cherry. }\end{array}$ \\
\hline
\end{tabular}

ORNAMENTAL VARIETIES.

\begin{tabular}{|c|c|c|c|}
\hline NAME. & & & RENARKS. \\
\hline $\begin{array}{l}\text { European Bird Cherry, } \\
\text { Large Double flowering, } \\
\text { Weeping, or All Saints', }\end{array}$ & $\cdot$ & $\dot{.}$ & $\begin{array}{l}\text { Beautiful flowers. } \\
\text { Delicate drooping branches. }\end{array}$ \\
\hline
\end{tabular}




\section{LIST OF CHERRIES,}

Of which, as yet, small trees or grafts only can be furnished.

Arch Duke.

Baumann's May.

Bigarreau de Mai?

Black Bigarreau of Savoy.

Buttner's Yellow.

Buttner's October Morello.

Downing's Red-cheek.
Flemish.

Gascoigne's Heart. Bleeding Heart.

Imperial Morello.

River's Early Amber.

Royal Duke.

Sparhawk's Honey.

\section{NECTARINES.}

$37 \frac{1}{2}$ CTS. EACH.

\begin{tabular}{|c|c|c|c|c|}
\hline NAMEE. & Size. & Flesh. & Season. & REMARKS. \\
\hline 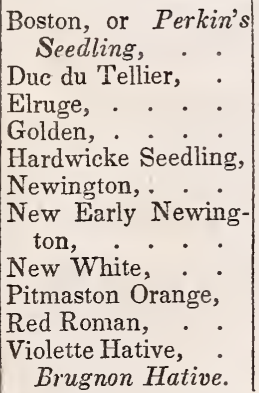 & $\begin{array}{c}\text { large } \\
\text { large } \\
\text { large } \\
\text { medium } \\
\text { large } \\
\text { large } \\
\text { large } \\
\text { large } \\
\text { large } \\
\text { large } \\
\text { large }\end{array}$ & $\begin{array}{l}\text { free } \\
\text { free } \\
\text { free } \\
\text { cling } \\
\text { free } \\
\text { cling } \\
\text { cling } \\
\text { free } \\
\text { free } \\
\text { cling } \\
\text { free }\end{array}$ & $\begin{array}{l}\text { b. Sept. } \\
\text { e. Aug. } \\
\text { b. Sept. } \\
\text { m. Sept. } \\
\text { Sept. } \\
\text { Sept. }\end{array}$ & $\begin{array}{l}\text { Superb, very large. } \\
\text { Excellent. } \\
\text { One of the finest. } \\
\text { New, fine, good bearer. } \\
\text { Good old sort. } \\
\text { Rich flavored cling. } \\
\text { Beautiful, great bearer. } \\
\text { Large and good. }\end{array}$ \\
\hline
\end{tabular}

[5 The following Nectarines are in course of propagation.

\begin{tabular}{|l|c|c|c|c|}
\hline NAME. & Size. & Flesh. & Season. & REMARIK. \\
\hline $\begin{array}{l}\text { Hunt's Tawuy, } \\
\begin{array}{l}\text { Murray, . } \\
\text { Peterborough, or } \\
\text { Vermont, }\end{array}\end{array}$ & $\begin{array}{c}\text { medium } \\
\text { medium } \\
\text { medium }\end{array}$ & $\begin{array}{c}\text { free } \\
\text { free } \\
\text { free }\end{array}$ & $\begin{array}{c}\text { Aug. } \\
\text { Aug. } \\
\text { e. Sept. }\end{array}$ & The best early sort. \\
\hline
\end{tabular}




\section{APRICOTS.}

PRICE $37 \frac{1}{2}$ CTS. EACH.

N. B. This fruit is grown on Plum stocks entirely, here.

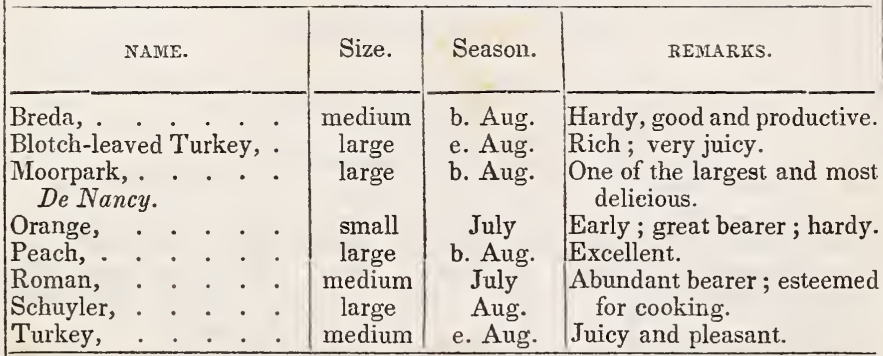

\section{LIST OF APRICOTS,}

Of which only small trees can be supplied this season.

\begin{tabular}{|c|c|c|c|c|c|}
\hline NAME. & & & Size. & Season. & REMARKS. \\
\hline $\begin{array}{l}\text { Black, . } \\
\text { Brussels, : } \\
\text { Early Red, } \\
\text { Gros Muscat, . } \\
\text { Hemskirke, . } \\
\text { Large Early, . } \\
\text { Royal, · . } \\
\text { Red Masculine, } \\
\text { White Masculine, }\end{array}$ & $\begin{array}{l}: \\
: \\
: \\
: \\
:\end{array}$ & $\begin{array}{l}\dot{ } \\
. \\
. \\
. \\
.\end{array}$ & $\begin{array}{l}\text { small } \\
\text { medium } \\
\text { large } \\
\text { large } \\
\text { large } \\
\text { large } \\
\text { large } \\
\text { small } \\
\text { small }\end{array}$ & $\begin{array}{l}\text { Aug. } \\
\text { Aug. } \\
\text { b. Aug. } \\
\text { e. July } \\
\text { e. July } \\
\text { m. July } \\
\text { e. July } \\
\text { July } \\
\text { July }\end{array}$ & $\begin{array}{l}\text { Juicy and excellent. } \\
\text { Very large and early. } \\
\text { Hardy, large and good. } \\
\text { Productive; second-rate. } \\
\text { Differs from the last only in } \\
\text { color. }\end{array}$ \\
\hline
\end{tabular}




\section{GRAPES.}

C I 1 옹․

FOREIGN GRAPES.

PRICE 50 TO 75 CENTS EACII.

\begin{tabular}{|c|c|c|c|c|}
\hline NAME. & Size. & Color. & $\begin{array}{l}\text { Shape of } \\
\text { berry. }\end{array}$ & REVIARKS. \\
\hline Black Cluster, . . & small & black & round & Hardy and sweet. \\
\hline $\begin{array}{l}\text { Black Hamburgh, . } \\
\text { Frankendale. } \\
\text { Victoria. }\end{array}$ & large & black & & $\begin{array}{l}\text { Delicious, large, and } \\
\text { first-rate in all re- } \\
\text { spects. }\end{array}$ \\
\hline $\begin{array}{l}\text { Black Lombardy, } \\
\text { West's St. Peter's. }\end{array}$ & large & black & round & $\begin{array}{l}\text { Rich flavor; requires } \\
\text { a vinery. }\end{array}$ \\
\hline $\begin{array}{l}\text { Black Prince, . } \\
\text { Black Portugal. }\end{array}$ & large & black & oval & Rich and delicious. \\
\hline Black St. Peter's, . & large & black & round & Sweet, rich and late. \\
\hline $\begin{array}{l}\text { Black Frontignan,. } \\
\text { Black Frontignac. }\end{array}$ & medium & black & round & $\begin{array}{l}\text { Musky, rich and excel- } \\
\text { lent. }\end{array}$ \\
\hline $\begin{array}{l}\text { Chasselas Musqué, } \\
\text { Esperione, · }\end{array}$ & $\begin{array}{l}\text { medium } \\
\text { large }\end{array}$ & $\begin{array}{l}\text { white } \\
\text { purple }\end{array}$ & $\begin{array}{l}\text { round } \\
\text { round }\end{array}$ & $\begin{array}{l}\text { Excellent. } \\
\text { Hardy, sweet and good }\end{array}$ \\
\hline $\begin{array}{c}\text { Early White Malva- } \\
\text { sia,. } . . \\
\end{array}$ & medium & & round & Swe \\
\hline $\begin{array}{l}\text { Grizzly Frontignan, } \\
\text { Red Frontignan. } \\
\text { IIuscat Gris. }\end{array}$ & medium & pl. red & - round & Muscat flavor. \\
\hline Miller's Burgundy, & small & black & oval & $\begin{array}{l}\text { Compact, sweet and } \\
\text { hardy. }\end{array}$ \\
\hline $\begin{array}{l}\text { Royal Muscadine,. } \\
\text { Chasselas de Fon- } \\
\text { tainbleau. } \\
\text { Golden Chasselas. }\end{array}$ & large & white & round & $\begin{array}{l}\text { Sweet, excellent and } \\
\text { hardy. }\end{array}$ \\
\hline Syrian, · . $\cdot$ & large & white & oval & $\begin{array}{l}\text { Enormous bunches; re- } \\
\text { quires fire heat. }\end{array}$ \\
\hline $\begin{array}{l}\text { White Sweetwater, } \\
\text { Chasselas Royale. }\end{array}$ & medium & white & round & $\begin{array}{l}\text { Pleasant flavor; good } \\
\text { bearer. }\end{array}$ \\
\hline $\begin{array}{c}\text { White Muscat of Al- } \\
\text { exandria,. }\end{array}$ & large & white & oval & Most delicious; re- \\
\hline White Rissling, . & small & & round & quires a vinery. \\
\hline White Tokay,. & large & white & oval & Sweet and rich. \\
\hline
\end{tabular}


CIA $\mathbf{A s}$ II.

NA T I V G RA P E S .

PRICE $37 \frac{1}{2}$ CTS. * +50 CTS.

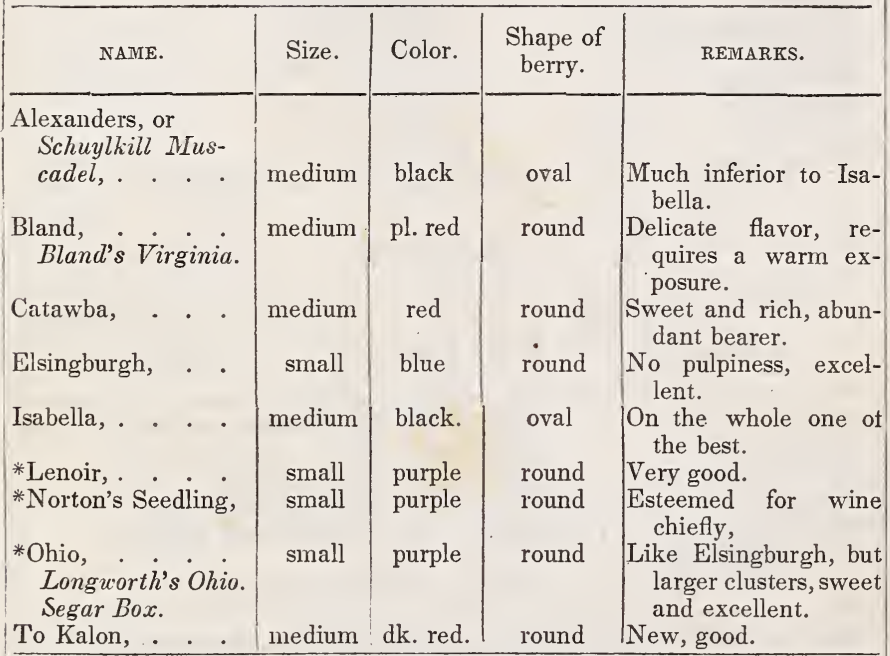

\section{GOOSE B E R R IES.}

PRICE 20 CTS. EACH.-(Fine Lancashire sorts.)

\begin{tabular}{l|l|}
\multicolumn{1}{c|}{ GREEN. } & \multicolumn{1}{c|}{ RED. } \\
Bates' Favorite. & British Crown. \\
Conquering Hero. & Crown Bob. \\
Governess. & Champagne. \\
Glory of Ratcliffe. & Farmer's Glory. \\
Green Walnut. & Hooper's Great Captain. \\
Green Hairy. & Keen's Seedling. \\
Green Gage. & Lancashire Lad. \\
Green Ocean. & Rifleman. \\
Greenwood. & Roaring Lion. \\
Independent. & Top Sawyer. \\
Jolly Angler. & Wilmot's Superb. \\
Jolly Farmer. & Warrington. \\
Jolly Nailer. & \\
Jolly Tar. & \\
\hline
\end{tabular}




\section{WHITE.}

Bonny Lass.

Bright Venus.

Cheshire Lass.

Great Britain.

Lady of the Manor.

Pigeon's Egg.

Sheba Queen.

Snowball.

Wellington's Glory.

Wintarton Lass.

White Eagle.

White Lion.

Whitesmith.

White Honey.

\section{YELLOW.}

Bunker Hill.

Duck-wing.

Early Sulphur.

Golden Drop.

Golden Fleece.

Golden Sovereign.

Golden Gourd.

Husbandman.

Jolly Gunner.

Rockwood.

Viper.

Yellow Ball.

\section{URRANT S.}

\begin{tabular}{|c|c|c|c|}
\hline NAME. & Color. & Price. & REMARKS. \\
\hline $\begin{array}{l}\text { Large Red Dutch,. } \\
\text { Large Red Dutch,. } \\
\text { May's Victoria, . } \\
\text { Champagne, } \\
\text { Black Naples, . } \\
\text { Large English Black. } \\
\text { Missouri Yellow Flower- } \\
\quad \text { ing, } \\
\text { Missouri Large Fruited, }\end{array}$ & $\begin{array}{l}\text { red } \\
\text { white } \\
\text { red } \\
\text { pl. red } \\
\text { black } \\
\text { blue } \\
\text { blue }\end{array}$ & $\begin{array}{rl}\$ 0 & 18 \\
0 & 18 \\
0 & 50 \\
0 & 18 \\
0 & 25 \\
0 & 37 \frac{1}{2} \\
0 & 50\end{array}$ & $\begin{array}{l}\text { Large, and the finest sorts } \\
\text { for general use. } \\
\text { New. } \\
\text { Pretty, and good. } \\
\text { Best black Currant. } \\
\text { Ornamental. } \\
\text { Large, pleasant fruit. }\end{array}$ \\
\hline
\end{tabular}

\section{RASPBERRIES。}

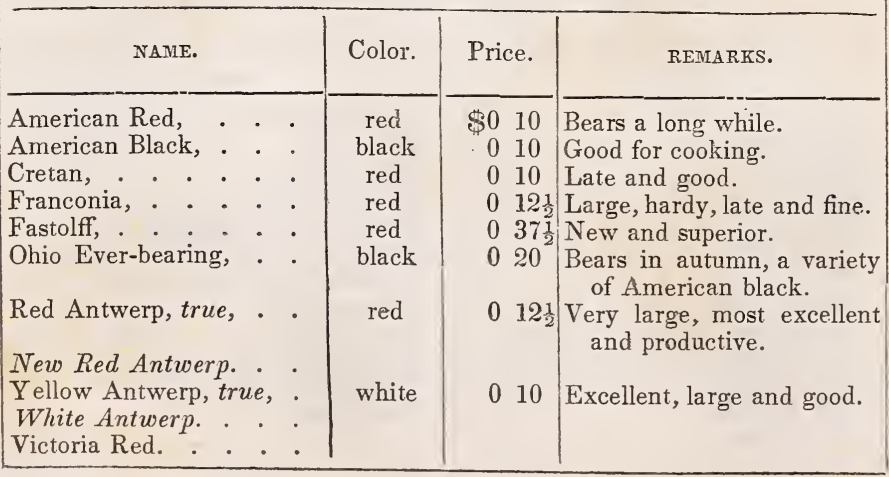


A L MONDS, FILBERTS, WALNUTS, \&c.

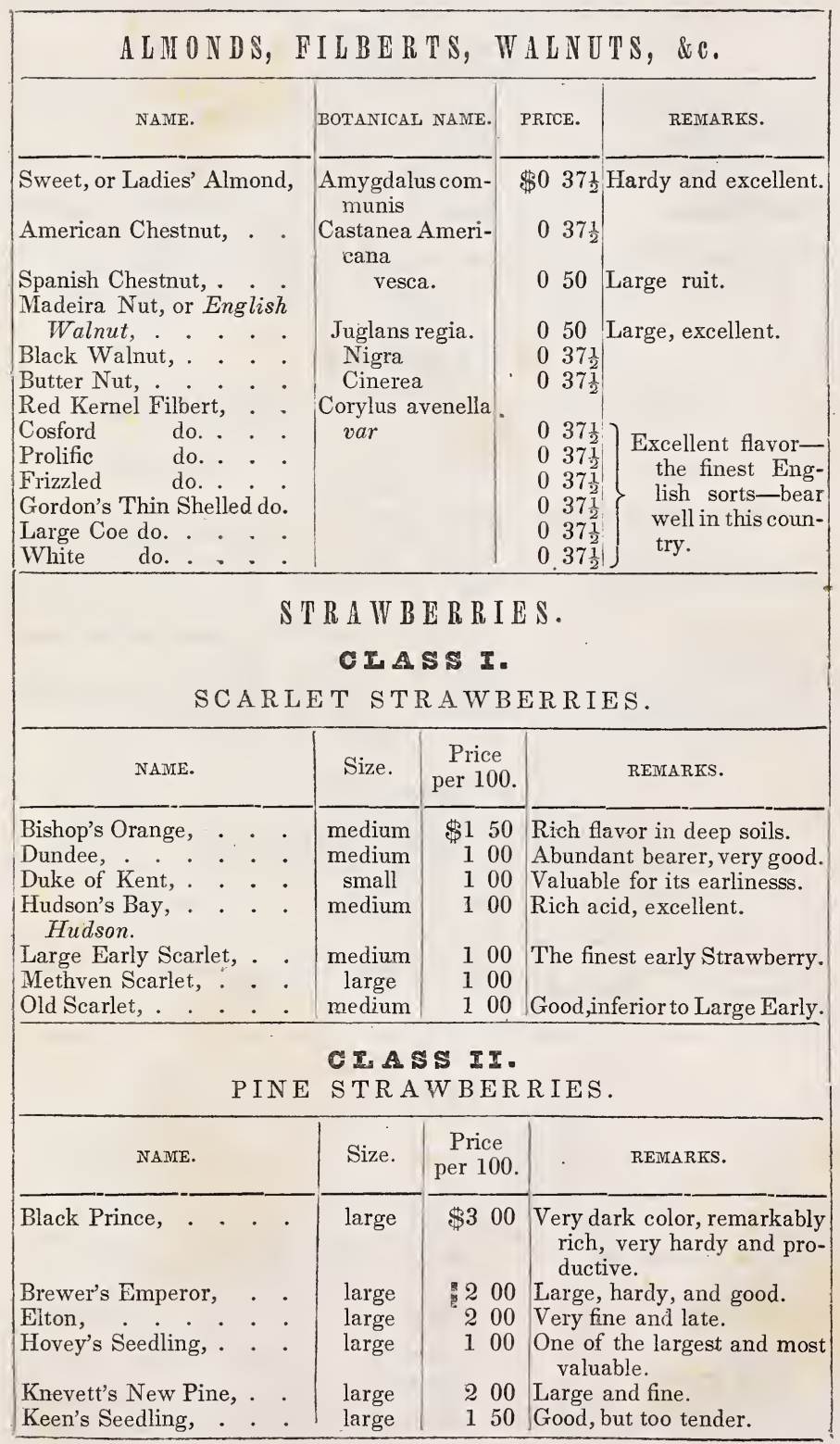




\begin{tabular}{|c|c|c|c|}
\hline NAME. & Size. & $\begin{array}{c}\text { Price } \\
\text { per } 100 .\end{array}$ & REMARKS. \\
\hline Myatt's Deptford Pine, & large & 300 & New, large, and excellent. \\
\hline Myatt's Eliza, . . & large & 200 & \\
\hline Myatt's British Queen, & large & 200 & $\begin{array}{l}\text { Very large, but not quite } \\
\text { hardy. }\end{array}$ \\
\hline Ross' Phœnix, . · · & large & 150 & $\begin{array}{l}\text { Exceedingly rich, large, and } \\
\text { hardy. }\end{array}$ \\
\hline Swainstone Seedling, . & medium & 200 & $\begin{array}{l}\text { Beautiful, delicious, bears a } \\
\text { long time. }\end{array}$ \\
\hline
\end{tabular}

\section{CIAS II.}

WOOD AND ALPINE STRAWBERRIES.

\begin{tabular}{|c|c|c|c|c|}
\hline NAME. & & Size. & $\begin{array}{c}\text { Price } \\
\text { per } 100 .\end{array}$ & REMARKS. \\
\hline $\begin{array}{l}\text { English Red Wood, } \\
\text { English White Wood, }\end{array}$ & & $\begin{array}{l}\text { small } \\
\text { small }\end{array}$ & $\begin{array}{rr}\$ 1 & 00 \\
1 & 00\end{array}$ & $\left\{\begin{array}{l}\text { Valuable standard sorts- } \\
\text { berries white and red- } \\
\text { bear with a little care } \\
\text { and for a long time. }\end{array}\right.$ \\
\hline $\begin{array}{l}\text { White Alpine, . } \\
\text { Red Alpine, } \\
\text { White Bush Alpine, } \\
\text { Red Bush Alpine, . }\end{array}$ & & $\begin{array}{l}\text { small } \\
\text { small } \\
\text { small } \\
\text { small }\end{array}$ & $\begin{array}{ll}1 & 00 \\
1 & 00 \\
2 & 00 \\
2 & 00\end{array}$ & $\left\{\begin{array}{l}\text { Excellent monthly bear- } \\
\text { ing sorts. } \\
\text { Do. the plants produce } \\
\text { no runners. }\end{array}\right.$ \\
\hline
\end{tabular}

CIA $\mathbf{A}$ I $\mathbf{V}$.

HAUTBOIS' STRAWBERRIES.

\begin{tabular}{|c|c|c|c|}
\hline NAMEE. & Size. & $\begin{array}{c}\text { Price } \\
\text { per } 100 .\end{array}$ & REMARKS. \\
\hline $\begin{array}{l}\text { Prolific or Conical, } \\
\text { French MIusk Hautbois. } \\
\text { Common, }\end{array}$ & $\begin{array}{c}\text { large } \\
\text { medium }\end{array}$ & $\begin{array}{rl}\$ 1 & 00 \\
1 & 00\end{array}$ & $\begin{array}{l}\text { Large, productive; musky } \\
\text { flavor. }\end{array}$ \\
\hline
\end{tabular}

Q UIN C E S.

\begin{tabular}{|c|c|c|c|}
\hline Common Names. & Botanical Names. & Price. & REMARKS. \\
\hline $\begin{array}{l}\text { Apple shaped, or } \\
\text { Orange. }\end{array}$ & Cydonia vulgaris. & $\$ 037$ & The flnest variety. \\
\hline Pear shaped. & - oblonga. & 037 & $\begin{array}{l}\text { Later, but inferior to } \\
\text { the above. }\end{array}$ \\
\hline $\begin{array}{l}\text { Portugal. } \\
\text { Japan Scarlet. } \\
\text {.Tapan Blush. }\end{array}$ & $\begin{array}{l}\text { lusitanica. } \\
\text { Japonica. } \\
\text { alba. }\end{array}$ & $\begin{array}{ll}0 & 50 \\
0 & 50 \\
0 & 50\end{array}$ & $\begin{array}{l}\text { Rather shy bearer. } \\
\text { Ornamental only. }\end{array}$ \\
\hline
\end{tabular}




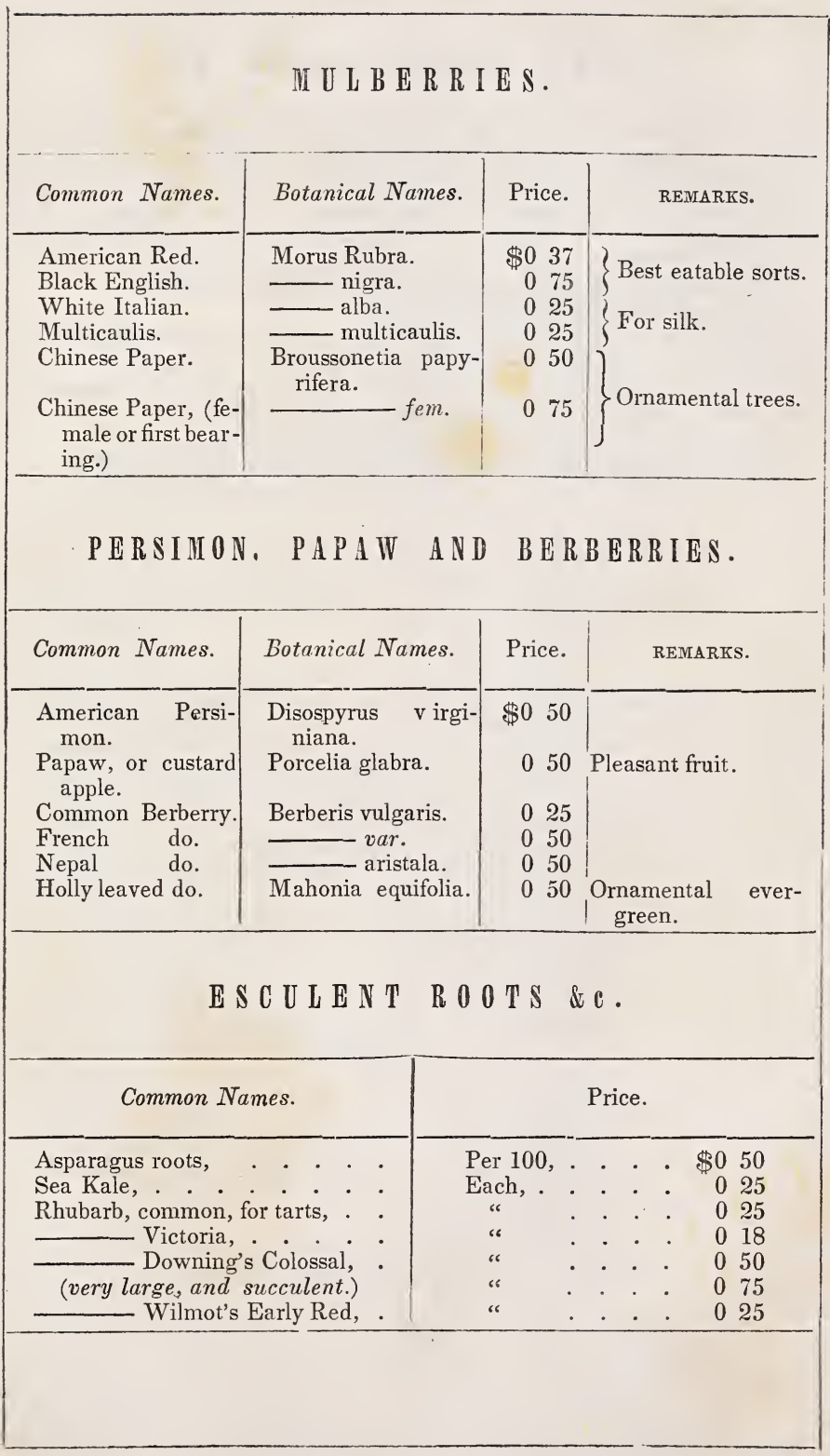




\section{SCIONS, HEDGE PLANTS. \& C.}

Scions, or grafts, of any of the Fruit-trees in the establishment, (including some not enumerated herein,) will be furnished at $25 \mathrm{cts}$. per dozen for apples, and 50 cts. per dozen for Pears, Plums, \&c. The price of a tree of the same sort will be charged for a less quantity. Scions of grapes at 5 to 12 dollars per 100 . The scions will be carefully packed and forwarded by EXPRESS if desired.

Orders should be received for the above in the fall or winter.

Cuttings of Osier Willows at $\$ 5$ per 1000.

Hawthorns for Hedges of the Washington Thorn, a hardy native sort at $\$ 6$ per 1000; of the Cockspur Thorn, \$6 per 1000.

BucктновN, (Rhamnus Catharticus,) for hedges, (admirably adapted to this climate, rapid growth and robust habit,) $\$ 15$ per 1000 .

Privet or Prim, for garden hedges, \$3 to 5 per 100.

American Arbor Vit e, for Evergreen hedges, $\$ 10$ to $\$ 30$ per 100. 


\title{
ORNAMENTAL TREES.
}

\section{CIASS I.}

\author{
DE C I U O U S.
}

50 CENTS EACH, EXCEPT THOSE MIARKED $\dagger$ WHICH ARE $37 \frac{1}{2}$ CENTS.

Common Names. $\quad \mid \quad$ Botanical Names.

Large White Horse Chestnut.

Ohio Buckeye.

Sugar Maple.

Scarlet Maple.

English Sycamore Maple.

- Cork Maple.

Variegated-leaved do.

Striped-barked, or Moose Wood.

Silver-leaved Maple, a beautiful tree.

Chinese Ailantus, or Celestial tree.

†European Alder, rapid growth.

Cut-leaved do.

†Double flowering Peach.

Scotch Weeping Birch.

White, or Paper do.

Judas Tree, or Red bud.

Catalpa Tree, showy flowers.

Spanish Chestnut, fine large eatable fruit.

†Common Chestnut.

Dwarf. do.

White Dogwood.

Double flowering Cherry.

Weeping Cherry.

†Bird Cherry.

Garland Deutzia.

Persimmon, or American Medlar.

†Common Beech.

Purple-leaved do.

Weeping do.

White Ash.

European Ash.

Weeping Ash.
Esculus Hippocastanum.

A pallida.

Acer saccharinum.

- rubrum.

- Pseudo-Plantanus.

- campestre.

- variegatum.

- striatum.

dasycarpum.

Ailantus glandulosa.

Alnus glutinosa. laciniata.

Amygdalus Persica, $f$. pl.

Betula alba, pendula. - papyracea.

Cercis canadensis.

Catalpa syringafolia.

Castanea vesca.

- americana.

Cornus Florida.

Cerasus sylvestris, $p$. semperfloreus.

Cerasus Padus.

Deutzia scabra.

Diosporus virginiana.

Fagus sylvatica.

- purpurea.

Fraxinus americana. excelsior. excelsior, pendula. 


\begin{tabular}{|c|c|}
\hline Common Names. & Botanical Names. \\
\hline $\begin{array}{l}\text { Three thorned Acacia, delicate } \\
\text { foliage. } \\
\text { Large spined do. } \\
\text { Kentucky Coffee Tree, a fine tree. } \\
\text { Tulip Tree, or White Wood, beau- } \\
\text { tiful. } \\
\text { †Sassafras. } \\
\text { Liquidamber, or Sweet Gum. } \\
\text { Madeira Nut, or English Walnut. } \\
\text { Black Walnut. } \\
\text { European Larch, a rapid growing, } \\
\text { picturesque tree. } \\
\text { American Larch, or Hacmatack. } \\
\text { Osage Orange, handsome foliage } \\
\text { and fruit. } \\
\text { Western Magnolia, or Cucumber } \\
\text { Tree. } \\
\text { Umbrella Magnolia, largeleaves and } \\
\text { flowers. 75 cents to \$1 50. } \\
\text { Large leaved Miagnolia, leaves } 2 \\
\text { feet long, and large white flowers. } \\
\text { \$1 to \$2 00. } \\
\text { Chinese White Magnolia, or Yulan } \\
\text { tree. \$2. } \\
\text { Soulange'sWhite and Purple do. } \$ 1 . \\
\text { Ash-leaved Maple, rapid growth. } \\
\text { Flowering Ash. } \\
\text { Oriental Plane, or Sycamore. } \\
\text { Silver Aspen, or Abele Tree, strik- } \\
\text { ing foliage and rapid growth. } \\
\text { Red-flowered Horse Chestnut. } \\
\text { tDouble flowering Apple. } \\
\text { European Mountain Ash, beautiful } \\
\text { foliage, and red berries. } \\
\text { Sorb, or Service Tree. } \\
\text { Japan Paulownia, new, fine flowers, } \\
\text { and large leaves. \$1. } \\
\text { Willow-leaved Oak. } \\
\text { tRed Oak. } \\
\text { English Oak. } \\
\text { Lucombe's Oak. } \\
\text { Large Overcup do. } \\
\text { Yellow Locust. } \\
\text { Honey Locust, (Pink flowering.) } \\
\text { Weeping Willow. } \\
\text { Ringlet, or Hoop-leaved Willow, } \\
\text { curious foliage. } \\
\text { Japan Ginko Tree. } \\
\text { European Linden, or Lime Tree. } \\
\text { American do. or Bass Wood. } \\
\text { Southern Cypress. } \\
\text { American White Elm. } \\
\text { English Elm. } \\
\text { Cornish Elm. }\end{array}$ & $\begin{array}{l}\text { macrophylla. } \\
\text { Magnolia conspicua. } \\
\text { Negundo fraxinifolia. } \\
\text { Ornus europeus. } \\
\text { Platanus orientale. } \\
\text { Populus alba. } \\
\text { Pavia rubra. } \\
\text { Pyrus Malus, } f . p l . \\
\text { aucuparia. } \\
\text { sorbus. } \\
\text { Paulownia imperialis. } \\
\text { Quercus phellos. } \\
\text { rubra. } \\
\text { robur. } \\
\text { Robinia pseud-acacia. } \\
\text { Salix Babylonica. } \\
\text { Salisburia adiantifolia. } \\
\text { Tilia europea. } \\
\text { Taxodium distichum. } \\
\text { Ulmus americana. } \\
\text { campestris. } \\
\end{array}$ \\
\hline
\end{tabular}


ORNAMENTAL TREES.

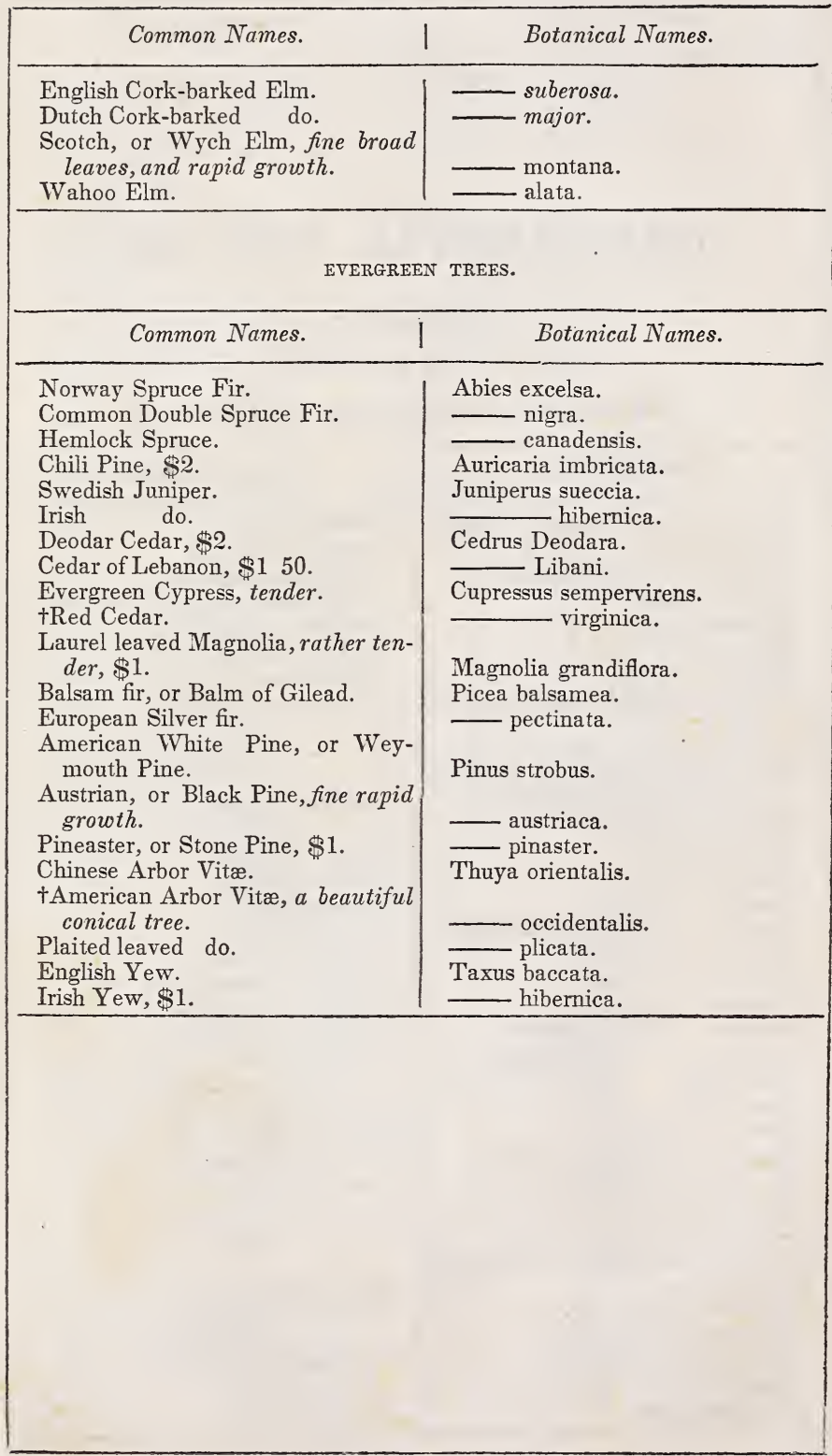




\section{ORNAMENTAL SHRUBS.}

\section{CIASS I.}

DECIDUOUS SHRUBS.

50 cTS. EACH, EXCEPT $\dagger$ WHICH ARE $37 \frac{1}{2}$ cTS.

\begin{tabular}{|c|c|}
\hline Common Names. & Botanical Names. \\
\hline $\begin{array}{l}\text { Western Papaw, or Custard Apple. } \\
\text { tIndigo Shrub. } \\
\text { tDouble flowering Almond. } \\
\text { tSouthernwood. } \\
\text { Groundsel tree. } \\
\text { tCommon Berberry. } \\
\text { French do. } \\
\text { White, or Virginia fringe tree, beau- } \\
\text { tiful. } \\
\text { Narrow leaved do. } \\
\text { Scarlet Japan Quince, or Pyrus ja- } \\
\text { ponica, brilliant flowers. } \\
\text { Blush, or White do. } \\
\text { Chinese Quince. } \\
\text { Fragrant Clethra. } \\
\text { Southern White do. } \\
\text { Cornelian Cherry, handsome fruit. } \\
\text { Bloody Dogwood. } \\
\text { Chinese Caragana. } \\
\text { Shrubby Caragana. } \\
\text { Siberian do., or Pea tree. } \\
\text { tLaburnum,or Golden Chain. } \\
\text { Oak leaved do. } \\
\text { Broad leaved do. } \\
\text { Scotch, or Alpine do. } \\
\text { Purple flowering do. } \\
\text { tCluster flowering do. } \\
\text { tSessile flowered do. } \\
\text { White Broom. } \\
\text { Purple Calycanthus, or Sweet scent- } \\
\text { ed Shrub. } \\
\text { Glaucous leaved do. } \\
\text { tGlabrous leaved do. } \\
\text { Yellow Bladder Senna. } \\
\text { Red flowered do. } \\
\text { tScorpion Senna. }\end{array}$ & $\begin{array}{l}\text { Asimina triloba. } \\
\text { Amorpha fruticosa. } \\
\text { Amygdalus nana. pl. } \\
\text { Artemesia abrotanum. } \\
\text { Baccharis halimifolia. } \\
\text { Berberis vulgaris. } \\
\text { Chionanthus virginica. } \\
\\
\text { Cydonia japonica. } \\
\text { alba. } \\
\text { Clethra alnifolia. } \\
\text { Cornus mascula. } \\
\text { Caragana chamaglima. } \\
\text { sanguinea. } \\
\text { Caragana arborescens. } \\
\text { Cytissus Laburnum. } \\
\text { quereifolium. } \\
\text { latifolia. } \\
\text { alpinus. } \\
\text { purpureus. } \\
\text { capitatus. }\end{array}$ \\
\hline
\end{tabular}




\begin{tabular}{|c|c|}
\hline Common Names. & Botanical Names. \\
\hline 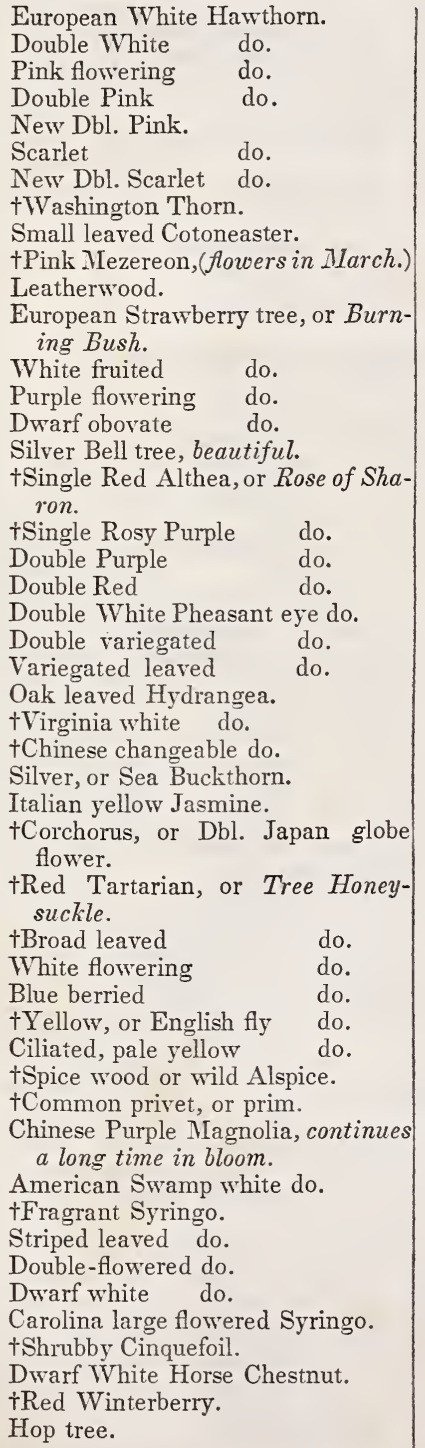 & 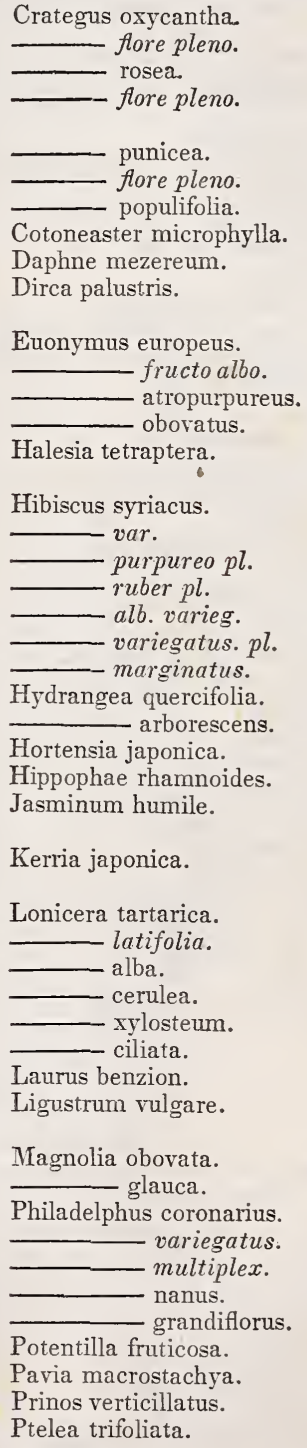 \\
\hline
\end{tabular}




\begin{tabular}{|c|c|}
\hline Common Names, & Botanical Names. \\
\hline $\begin{array}{l}\text { Chinese Tree Pæony, superb flowers, } \\
\text { \$1. } \\
\text { Poppy flowered do. 75 cts. } \\
\text { Venetian Sumac, or Purple fringe } \\
\text { tree. } \\
\text { †Black Buckthorn. } \\
\text { †Yellow Missouri Currant, fragrant } \\
\text { flowers. } \\
\text { New large fruited do. } \\
\text { Crimson flowering do. } \\
\text { †Rose Acacia. } \\
\text { †Rose flowering Bramble. } \\
\text { Buffalo berry, or Silvery leaved } \\
\text { Shepherdia, fine fruit. } \\
\text { †Guelder-rose Spirea. } \\
\text { †Cluster flowering do. } \\
\text { †Red flowering Spirea. } \\
\text { †Early Sorb-leaved do. } \\
\text { †White Willow leaved Spirea. } \\
\text { †Rose colored do. } \\
\text { †St. Peter's Wreath } \\
\text { Nepal Red } \\
\text { †Three leaved Bladder Nut. } \\
\text { †Snowberry. } \\
\text { †Red fruited Indian Currant. } \\
\text { Sweet flowering Willow. } \\
\text { †White Lilac. } \\
\text { †Purple do. } \\
\text { Purple Persian do. } \\
\text { White Persian Lilac. } \\
\text { Cut leaved do. } \\
\text { Large Siberian do. } \\
\text { French Tamarisk. } \\
\text { tSnowball, or Guelder-rose. } \\
\text { Cranberry Viburnum. } \\
\text { †Early White Viburnum. } \\
\text { Maple leaved do. } \\
\text { Parsley leaved Zanthorhiza. }\end{array}$ & 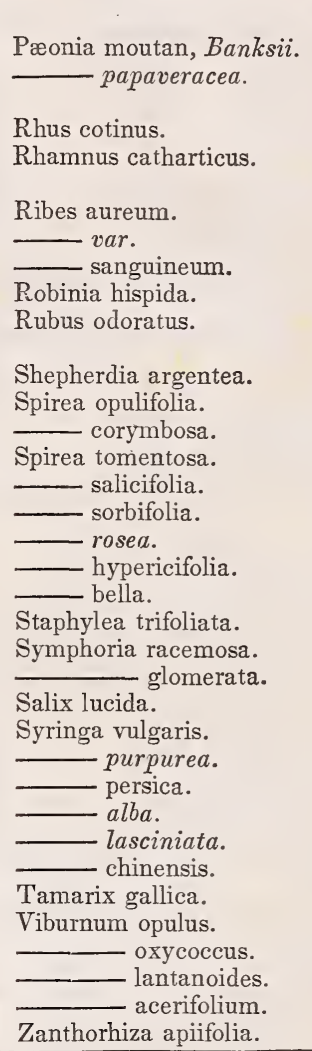 \\
\hline
\end{tabular}

\section{CIASII.}

EVERGREE SHRBS.

\begin{tabular}{|c|c|}
\hline Common Names. & Botanical Names. \\
\hline $\begin{array}{l}\text { †Common Dwarf Box. } \\
\text { Striped tree Box. } \\
\text { Shrubby Horsetail. } \\
\text { English Holly. } \\
\text { Silver striped Euonymus. } \\
\text { Silver striped Holly, } \$ 1 \text {. } \\
\text { Gold striped do. } \$ 1 \text {. } \\
\text { Broad leaved Kalmia, or Laurel. }\end{array}$ & $\begin{array}{l}\text { Buxus sempervirens. } \\
\text { Ephedra distachya. } \\
\text { Euonymus japonicus, fol. arg. } \\
\text { Ilex aquifolium. } \\
\text { arg. varieg. } \\
\text { Kalmia latifolia. }\end{array}$ \\
\hline
\end{tabular}




\begin{tabular}{|c|c|}
\hline Common Names. & Botanical Names. \\
\hline $\begin{array}{l}\text { Holly leaved Berberry. } \\
\text { Clustered Mahonia, beautiful. } \\
\text { American Rhododendron. } \\
\text { English Pontic Rhododendron, } 75 \mathrm{c} \text {. } \\
\text { White do. } \\
\text { Rose do. } 75 \mathrm{cts} \text {. } \\
\text { Red do. } 75 \mathrm{cts} \text {. } \\
\text { Magnolia leaved do. } \$ 1 \text { fts. } \\
\end{array}$ & 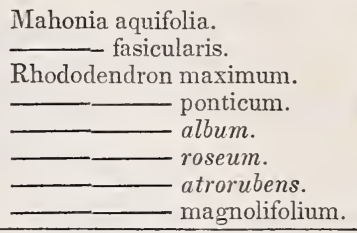 \\
\hline
\end{tabular}

\section{VINES AND CLIMBING SHRUBS.}

THOSE NOT MARKED, 50 CTS.; $† 37 \frac{1}{2}$ cTS. EACH.

\begin{tabular}{|c|c|}
\hline Common Names. & Botanical Names. \\
\hline $\begin{array}{l}\text { Birthwort, or Dutchman's Pipe. } \\
\text { Downy leaved do. } \\
\text { Virginia creeper. } \\
\text { Scarlet trumpet flower. } \\
\text { Chinese large flowered do. beautiful. } \\
\text { European sweet scented Clematis. } \\
\text { Red flowered do. } \\
\text { Double red do. } \\
\text { Purple flowered do. } \\
\text { Blue flowered do. } \\
\text { Bell flowered Th cts. } \\
\text { Japan double White do. } \\
\text { superb. } \\
\text { tCommon white Clematis. } \\
\text { †Late flowering do. } \\
\text { Siebold's new white and purple do. } \\
\text { European Ivy. } \\
\text { Irish, or Giant Ivy. } \\
\text { White flowering Jasmine. } \\
\text { tMonthly fragrant Honeysuckle. } \\
\text { Yellow flowered do. } \\
\text { Large Orange Colored do. } \\
\text { Chinese twining, beautiful foliage } \\
\text { and flowers. } \\
\text { tScarlet trumpet Monthly Honey- } \\
\text { suckle. } \\
\text { Yellow trumpet Monthly do. } \\
\text { tSmall flowered } \\
\text { Canadian Moonseed. } \\
\text { Periploca, or Virginian Silk. } \\
\text { Climbing Roses, see Roses. } \\
\text { Double White Bramble. } \\
\text { Chinese Wistaria, or Glycine, beau- } \\
\text { tiful pendulous flowers. }\end{array}$ & 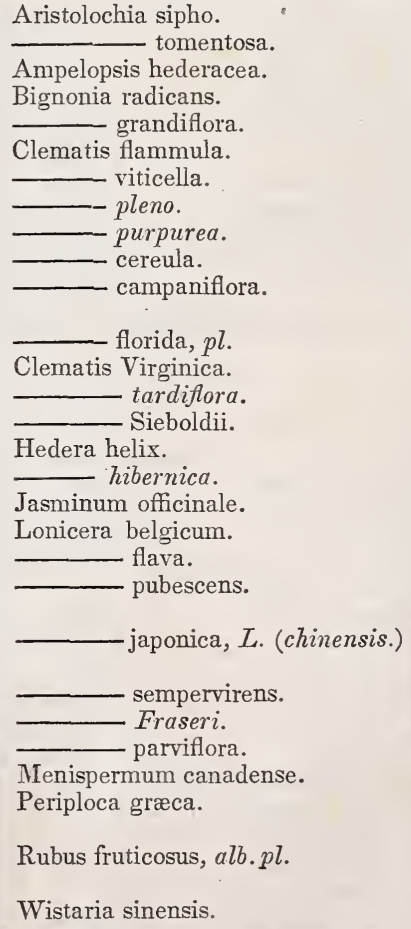 \\
\hline
\end{tabular}




\section{R O S E S.}

FIRST DIVISION.- - HARDY ROSES, THAT BLOOM BUT ONCE.

\section{H Y B R D CHINA ROSES.}

(In the abbreviation of the form of the flowers. cup. signifies cupped; exp. expanded ; comp. compact, and glob. globular.)

\begin{tabular}{|c|c|c|c|c|}
\hline NAME. & & Form. & Color. & Price. \\
\hline $\begin{array}{l}\text { Belle de Rosny, . } \\
\text { Bouquet Blanc, . } \\
\text { Cerisette, . } \\
\text { Celine, . } \\
\text { Chateleine, . } \\
\text { George IV, . } \\
\text { Gen. Thiars, . } \\
\text { Hybrid Blanche, } \\
\text { La Tourterelle, } \\
\text { Ne Plus Ultra, . } \\
\text { Petit Pierre,. } \\
\text { Riego, . } \\
\text { Roi de Prusse, : } \\
\text { Roi de Hybrides, } \\
\text { Victor Tracy, . }\end{array}$ & 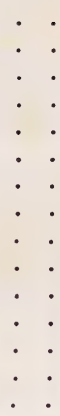 & $\begin{array}{l}\text { cup. } \\
\text { exp. } \\
\text { exp. } \\
\text { cup. } \\
\text { glob. } \\
\text { glob. } \\
\text { glob. } \\
\text { cup. } \\
\text { cup. } \\
\text { glob. } \\
\text { comp. } \\
\text { cup. } \\
\text { cup. } \\
\text { cup. } \\
\text { glob. }\end{array}$ & 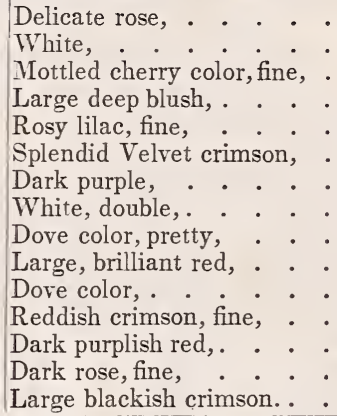 & $\begin{array}{ll}\$ 0 & 75 \\
0 & 75 \\
0 & 50 \\
0 & 50 \\
0 & 50 \\
0 & 50 \\
0 & 50 \\
0 & 50 \\
0 & 50 \\
0 & 50 \\
0 & 50 \\
0 & 50 \\
0 & 50 \\
0 & 75 \\
0 & 50\end{array}$ \\
\hline
\end{tabular}

FRENCH, PROVENCE AND DAMASK ROSES.

\begin{tabular}{|c|c|c|c|}
\hline NAME. & Form. & Color. & Price. \\
\hline 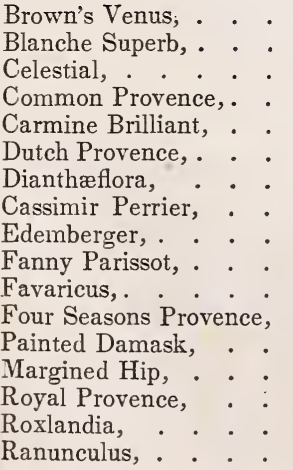 & $\begin{array}{l}\text { cup. } \\
\text { comp. } \\
\text { cup. } \\
\text { glob. } \\
\text { cup. } \\
\text { glob. } \\
\text { comp. } \\
\text { cup. } \\
\text { comp. } \\
\text { comp. } \\
\text { comp. } \\
\text { exp. } \\
\text { comp. } \\
\text { cup. } \\
\text { glob. } \\
\text { cup. } \\
\text { comp. }\end{array}$ & 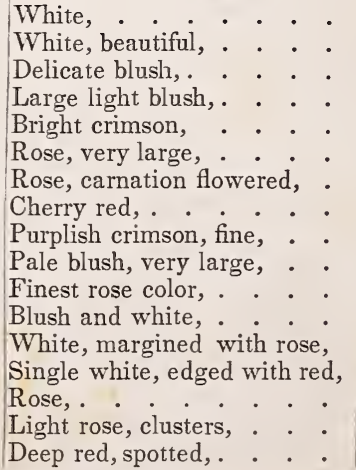 & $\begin{array}{ll}\$ 0 & 50 \\
0 & 50 \\
0 & 25 \\
0 & 25 \\
0 & 25 \\
0 & 37 \frac{1}{2} \\
0 & 50 \\
0 & 50 \\
0 & 50 \\
0 & 50 \\
0 & 50 \\
0 & 50 \\
0 & 50 \\
0 & 37 \frac{1}{2} \\
0 & 37 \frac{1}{2} \\
0 & 37 \frac{1}{2} \\
0 & 37 \frac{1}{2}\end{array}$ \\
\hline
\end{tabular}


R O S E S.

\begin{tabular}{|c|c|c|c|}
\hline NAMIE. & Form. & Color. & Price. \\
\hline $\begin{array}{l}\text { Relour's Purple, . } \\
\text { Snowball,. } \\
\text { Striped Unique, . } \\
\text { St. Francis, } \\
\text { Trés Charmante, } \\
\text { Triomphe d'Abbeyville, }\end{array}$ & $\begin{array}{l}\text { glob. } \\
\text { cup. } \\
\text { comp. } \\
\text { comp. } \\
\text { comp. } \\
\text { comp. }\end{array}$ & $\begin{array}{l}\text { Bright purplish crimson,. } \\
\text { Beautiful creamy white,. } \\
\text { White, striped with red,. } \\
\text { Light rose, . . } \\
\text { Cherry color, . } \\
\text { Marbled, deep red, }\end{array}$ & $\begin{array}{ll}0 & 37 \frac{1}{2} \\
0 & 37 \frac{1}{2} \\
0 & 75 \\
0 & 37 \frac{1}{2} \\
0 & 50 \\
0 & 50\end{array}$ \\
\hline
\end{tabular}

\section{LIMBING ROSES.}

* Are rather tender, and require covering.

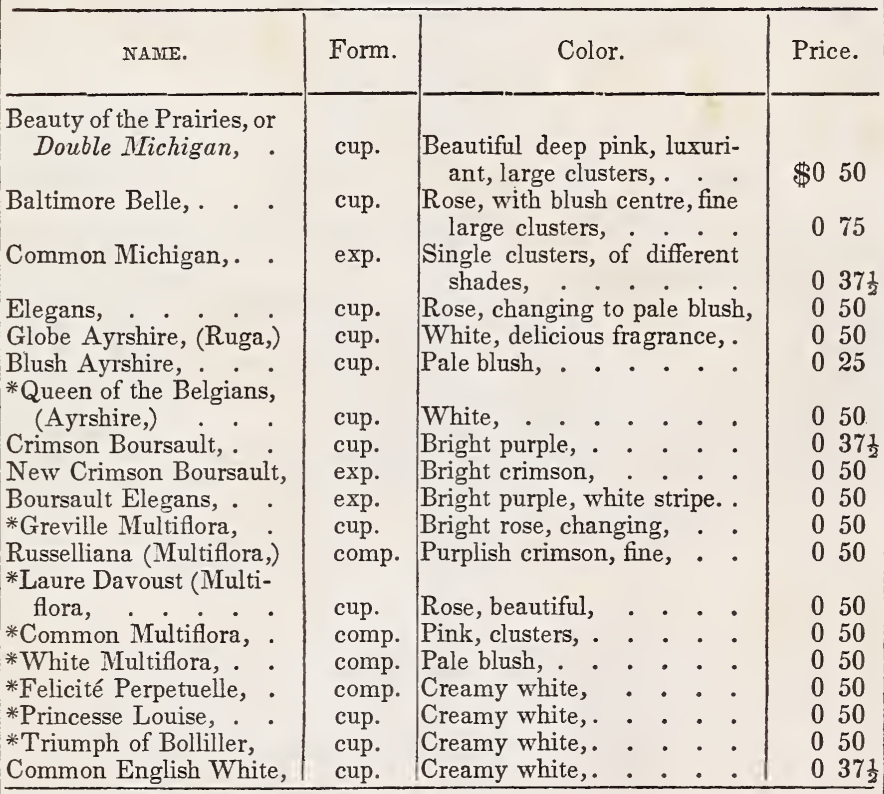

MOSS ROSES.

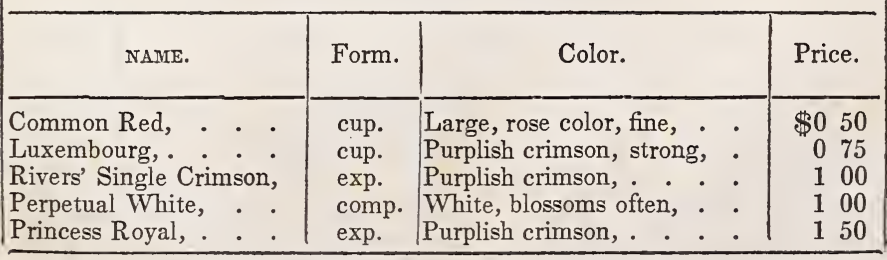




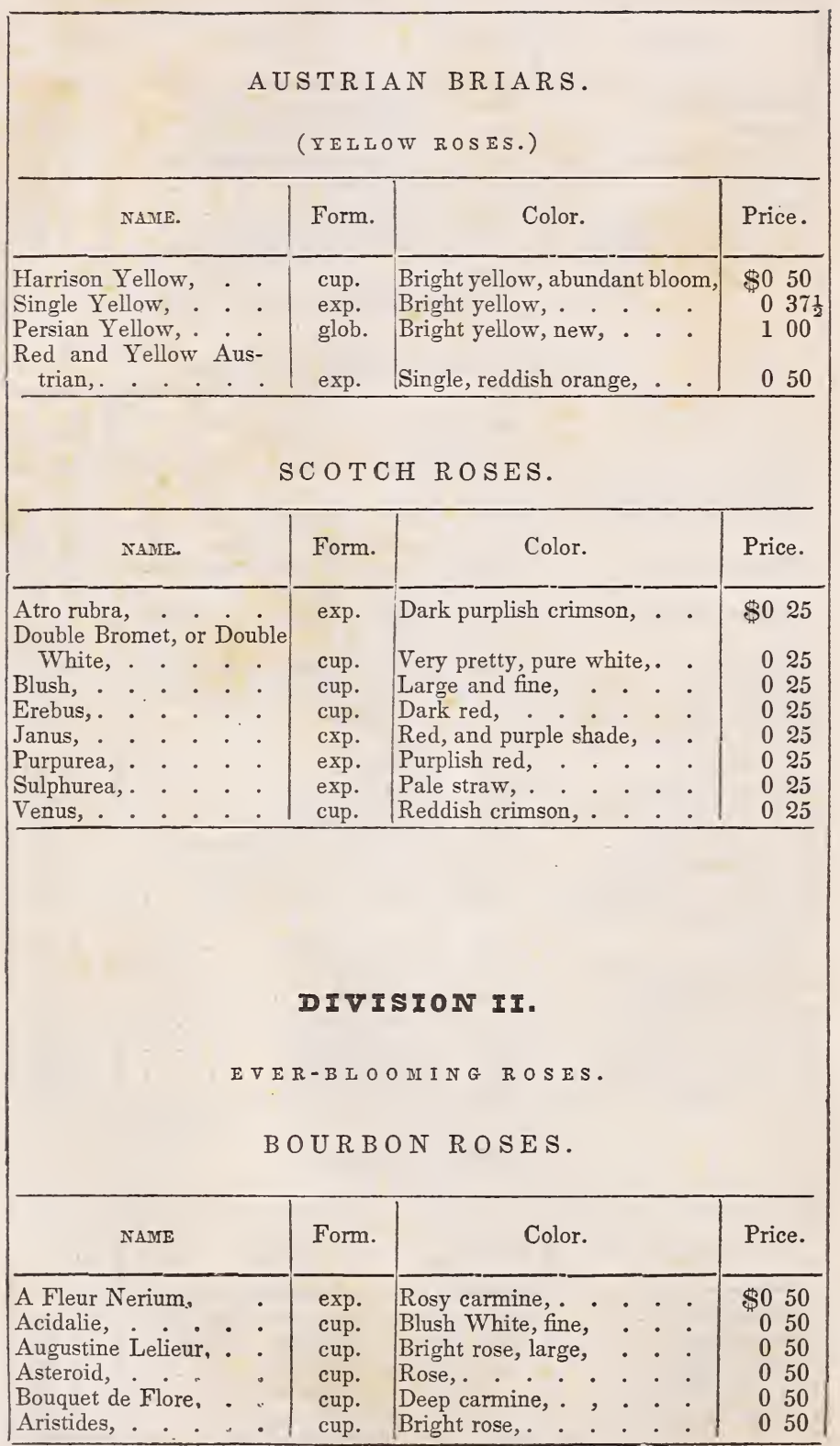




\begin{tabular}{|c|c|c|c|}
\hline NAME. & Form. & Color. & Price. \\
\hline 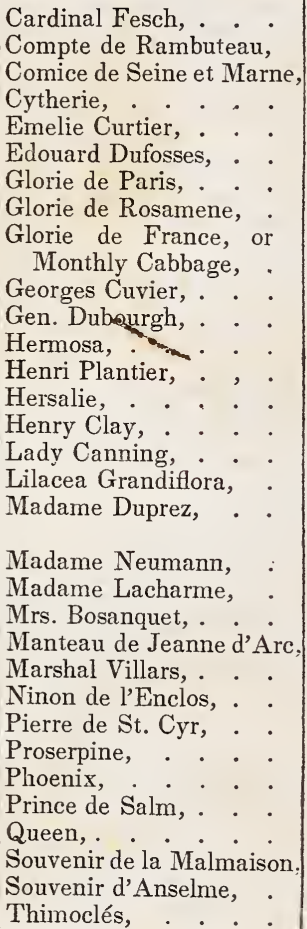 & $\begin{array}{l}\text { cup. } \\
\text { cup. } \\
\text { cup. } \\
\text { cup. } \\
\text { comp. } \\
\text { cup. } \\
\text { cup. } \\
\text { exp. } \\
\text { cup. } \\
\text { cup. } \\
\text { cup. } \\
\text { cup. } \\
\text { cup. } \\
\text { cup. } \\
\text { cup, } \\
\text { cup. } \\
\text { cup. } \\
\text { glob. }\end{array}$ & 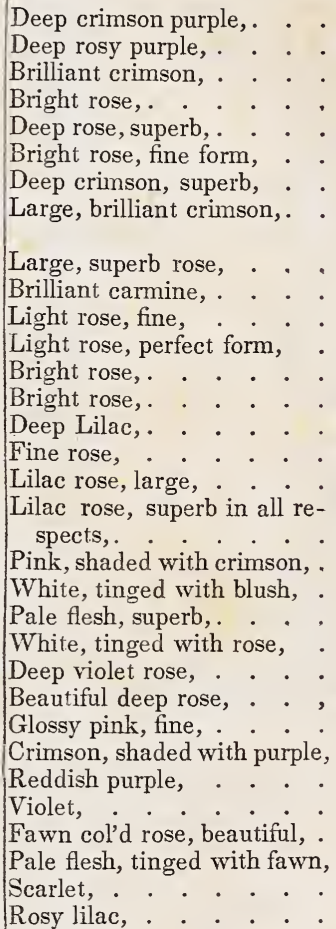 & $\begin{array}{ll}0 & 50 \\
0 & 50 \\
0 & 50 \\
0 & 50 \\
0 & 50 \\
0 & 50 \\
0 & 50 \\
0 & 50 \\
& \\
0 & 50 \\
0 & 50 \\
0 & 50 \\
0 & 50 \\
0 & 50 \\
0 & 50 \\
0 & 50 \\
0 & 50 \\
0 & 50 \\
& \\
0 & 50 \\
0 & 50 \\
0 & 50 \\
0 & 50 \\
0 & 50 \\
0 & 50 \\
0 & 50 \\
0 & 50 \\
0 & 50 \\
0 & 50 \\
0 & 50 \\
0 & 50 \\
0 & 50 \\
0 & 50 \\
0 & 50\end{array}$ \\
\hline
\end{tabular}

The Bourbon roses are the greatest acquisition which our flower gardens have received in the present age. With the invaluable habit of blooming the whole season, they unite the most delicious fragrance, vigorous and handsome habit, and broad and glossy foliage. Southward of this they are quite hardy, and here it is only necessary to throw over them some leaves, or a slight coat of litter, at the approach of winter, to be removed as soon as the spring opens.

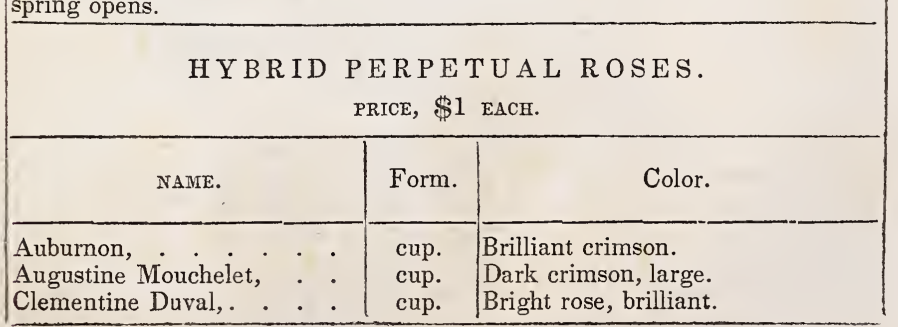




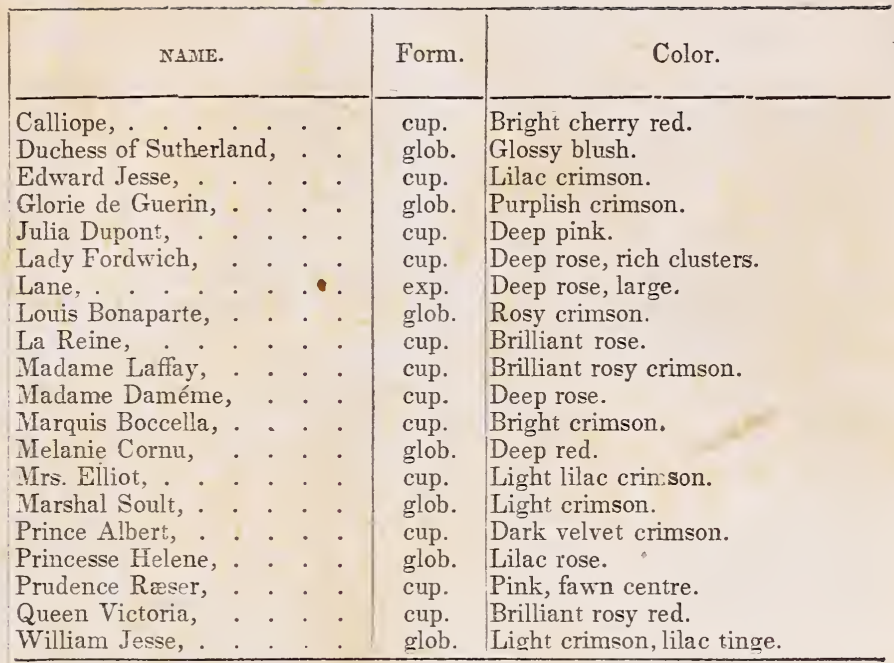

This newly originated class of roses is the most scarce and highly prized even in Europe, and has but lately been introduced here; perfectly hardy, ever-blooming, and of great beauty of form and color, the Hybrid Perpetuals will, no doubt, as soon as they become more plentiful, be considered the greatest favorites in all gardens.

CHINA, OR BENGAL ROSES.

$37 \frac{1}{2}$ TO 50 cENTS EACH.

\begin{tabular}{|c|c|c|c|}
\hline YAVE. & & Form. & Color. \\
\hline $\begin{array}{l}\text { Archduke Charles, . } \\
\text { Admiral de Rigney, } \\
\text { Alzande, . . . . } \\
\text { Baroune Delaage, . } \\
\text { Belle de Florence, . } \\
\text { Belle Archinto, . . } \\
\text { Belle Isidore, . . } \\
\text { Beau Carmin, . . } \\
\text { Clara Sylvain, . . } \\
\text { Centifolia, . . . } \\
\text { Cramoisie supérieure, } \\
\text { pina, . . . } \\
\text { Eugène Pirolle,. } \\
\text { Eugène Beauharnois, } \\
\text { Fenelon, . . . . } \\
\text { Hortensia, . . . } \\
\text { Hibbertia, . . . } \\
\text { Icteros, . . . }\end{array}$ & 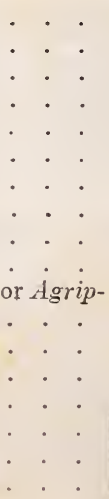 & $\begin{array}{l}\text { cup. } \\
\text { cup. } \\
\text { glob. } \\
\text { cup. } \\
\text { cup. } \\
\text { cup. } \\
\text { cup. } \\
\text { cup. } \\
\text { glob. } \\
\text { glob. } \\
\text { cup. } \\
\text { glob. } \\
\text { cup. } \\
\text { cup. } \\
\text { glob. } \\
\text { glob. } \\
\text { cup. }\end{array}$ & $\begin{array}{l}\text { Rose, changing to crimson. } \\
\text { Light rose. } \\
\text { White lilac tinge. } \\
\text { Deep purplish red. } \\
\text { Light carmine, large. } \\
\text { Pale flesh, pink edge. } \\
\text { Deep rose. } \\
\text { Purple maroon, shaded. } \\
\text { Pure white, beautiful. } \\
\text { Pale rose. } \\
\text { Rich crimson. } \\
\text { Delicate pink, fine. } \\
\text { Bright amaranth. } \\
\text { Pale blush. } \\
\text { Deep rose. } \\
\text { Dark rose. } \\
\text { Creamy white. }\end{array}$ \\
\hline
\end{tabular}




\begin{tabular}{|c|c|c|}
\hline NAME. & Form. & Color. \\
\hline 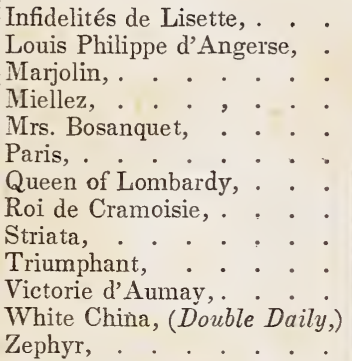 & $\begin{array}{l}\text { glob. } \\
\text { cup. } \\
\text { glob. } \\
\text { cup. } \\
\text { cup. } \\
\text { cup. } \\
\text { cup. } \\
\text { cup. } \\
\text { exp. } \\
\text { cup. } \\
\text { cup. } \\
\text { exp. } \\
\text { exp. }\end{array}$ & $\begin{array}{l}\text { Fine white, large. } \\
\text { Very fine crimson. } \\
\text { Dark red, large. } \\
\text { Lemon white. } \\
\text { Pale flesh. } \\
\text { Bright crimson. } \\
\text { Cherry color, exquisite. } \\
\text { Rich deep crimson. } \\
\text { Striped bark, curious. } \\
\text { Deep crimson. } \\
\text { Reddish pink. } \\
\text { Pure white. } \\
\text { Peach blossom, rose centre. }\end{array}$ \\
\hline
\end{tabular}

With a very slight covering in winter, these beautiful roses may be grown in the open border with the greatest success.

\section{NOISETTE ROSES.}

$37 \frac{1}{2}$ TO 50 cENTS EACH.

\begin{tabular}{|c|c|c|c|c|}
\hline NAMEE. & & & Form. & Color. \\
\hline 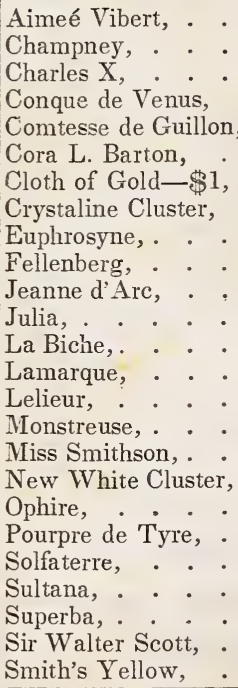 & & 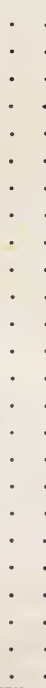 & $\begin{array}{l}\text { cup. } \\
\text { exp. } \\
\text { comp. } \\
\text { cup. } \\
\text { cup. } \\
\text { cup. } \\
\text { glob. } \\
\text { cup. } \\
\text { cup. } \\
\text { cup. } \\
\text { cup. } \\
\text { cup. } \\
\text { cup. } \\
\text { cup. } \\
\text { cup. } \\
\text { cup. } \\
\text { exp. } \\
\text { cup. } \\
\text { cup. } \\
\text { cup. } \\
\text { cup. } \\
\text { cup. } \\
\text { cup. } \\
\text { cup. } \\
\text { cup. }\end{array}$ & $\begin{array}{l}\text { Pure white, beautiful. } \\
\text { Light blush. } \\
\text { Light red. } \\
\text { White, flesh colored centre. } \\
\text { Bright rose. } \\
\text { Large rosy pink. } \\
\text { Pure yellow, large. } \\
\text { Pale blush. } \\
\text { Pale fawn. } \\
\text { Bright crimson. } \\
\text { Pure white. } \\
\text { Bright crimson. } \\
\text { Pale rosy white. } \\
\text { Yellowish white. } \\
\text { Brilliant crimson. } \\
\text { Lemon, very large. } \\
\text { Blush. } \\
\text { Light blush. } \\
\text { Nankin. } \\
\text { Bright sulphur. } \\
\text { Light blush. } \\
\text { Delicate pink. } \\
\text { Purplish rose. } \\
\text { Fine yellow. } \\
\text { Crimson purple. }\end{array}$ \\
\hline
\end{tabular}

The Noisettes are hardier than the Bengals, of fine climbing habit, and produce abundant clusters of flowers during the whole growing season. 
TEA SCENTED ROSES.

37 то 50 cTs. ЕАCH.

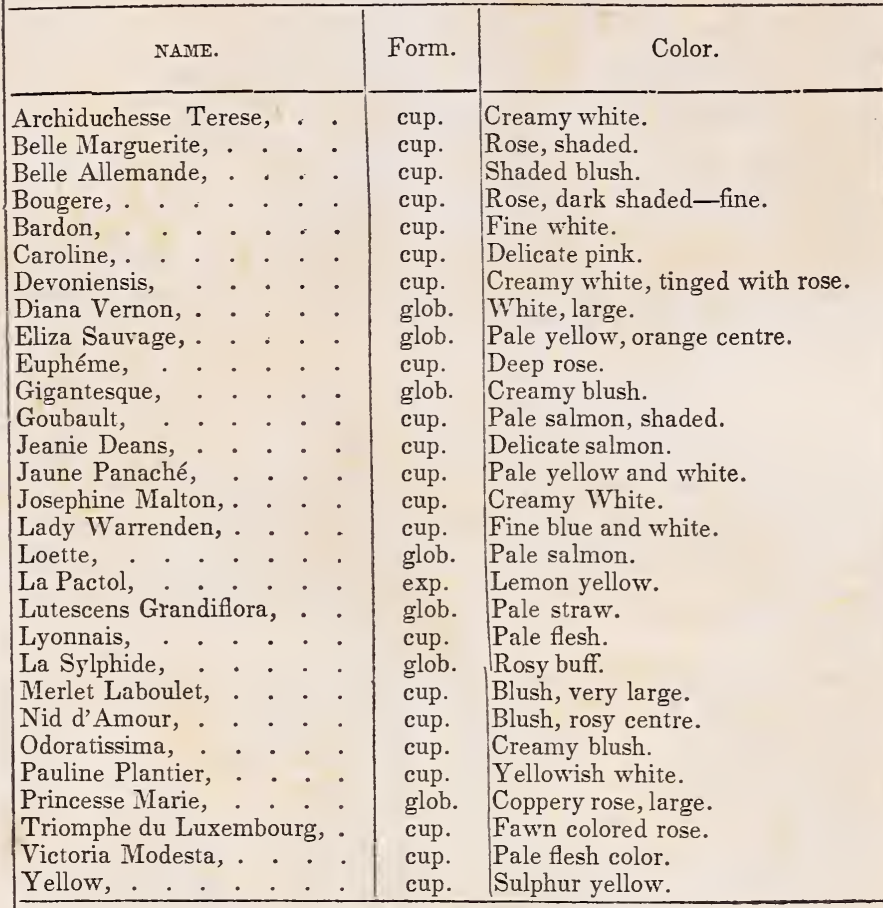

MISCELLANEOUS ROSES.

37 TO 50 CENTS EACH.

\begin{tabular}{|c|c|c|c|}
\hline NAMIE. & & Form. & Color. \\
\hline $\begin{array}{l}\text { Lady Banks' Yellow, . } \\
\text { Lady Banks' White, . } \\
\text { Lawrencia, Blush,. } \\
\text { Lawrencia Rubra,. } \\
\text { Microphylla Rubra, } \\
\text { Microphylla Alba, }\end{array}$ & 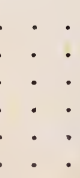 & $\begin{array}{l}\text { cup. } \\
\text { cup. } \\
\text { cup. } \\
\text { cup. } \\
\text { comp. } \\
\text { cup. }\end{array}$ & $\begin{array}{l}\text { Yellow. } \\
\text { Pure white, fragrant. } \\
\text { Light rose. } \\
\text { Crimson. } \\
\text { Lilac rose. } \\
\text { Large white. }\end{array}$ \\
\hline
\end{tabular}




\section{NEW PICOTEE CARNATIONS.}

\section{PRICE 25 CENTS EACH.}

The following are very beautiful FICOTEES raised at this establishment, and selected from among a great number of fine seedlings. To a greater variety of color, and bigher fragrance than the Flake and Bizarre carnations, they unite greater hardihood and therefore succeed perfectly in this climate.

\begin{tabular}{|c|c|c|c|c|c|}
\hline & & & & & Color. \\
\hline 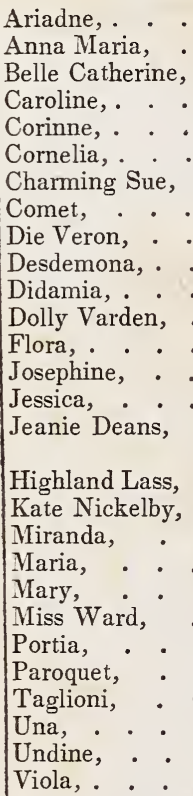 & & 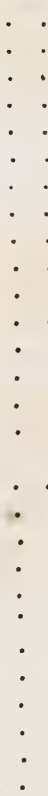 & $\begin{array}{cc}\cdot & \cdot \\
\cdot & \cdot \\
\cdot & \cdot \\
\cdot & \cdot \\
\cdot & \cdot \\
\cdot & \cdot \\
\cdot & \cdot \\
\cdot & \cdot \\
\cdot & \cdot \\
\cdot & \cdot \\
\cdot & \cdot \\
\cdot & \cdot \\
\cdot & \cdot \\
\cdot & \cdot \\
\cdot & \cdot \\
\cdot & \cdot\end{array}$ & $\begin{array}{l}\dot{ } \\
\dot{ } \\
\dot{ } \\
\dot{.} \\
\dot{.}\end{array}$ & $\begin{array}{l}\text { Pale cream, pencilled with scarlet. } \\
\text { Changeable rose. } \\
\text { Straw, edged with crimson. } \\
\text { Salmon, striped with crimson. } \\
\text { Light sulphur, touched with purple. } \\
\text { White, closely striped with crimson. } \\
\text { Scarlet, striped with crimson and purple. } \\
\text { Scarlet. } \\
\text { Large white, dashed with scarlet. } \\
\text { Large, dark purple edge. } \\
\text { White edged and pencilled with crimson. } \\
\text { Purplish-brownish edge, very fragrant. } \\
\text { White, pink edge. } \\
\text { White, pencilled with light crimson. } \\
\text { Cream, with scarlet edge. } \\
\text { Yellow, edged and shaded with dark crim- } \\
\text { son. } \\
\text { Scarlet, striped with crimson. } \\
\text { Sulphur edged with purple. } \\
\text { Salmon, rose edge. } \\
\text { White, dark crimson edge. } \\
\text { White, edged and striped with purple. } \\
\text { White, edged with purple. } \\
\text { Bright red. } \\
\text { Yellowish, fawn, and blush. } \\
\text { White, laced with crimson. } \\
\text { Pure white. } \\
\text { Pure white, touched with pale purple. } \\
\text { Yellow, crimson edge. }\end{array}$ \\
\hline
\end{tabular}

Bizarre, and Flake Carnations, of some of the best English sorts, at 50 cts. each.

Brussels and Paisley Pinks, of different sorts, 20 cts. each. 


\section{SELECT HERBACEOUS AND BULBOUS PLANTS,}

OR

PERRENNIAL BORDER FLOWERS.

20 TO 50 CENTS EACH.

\begin{tabular}{|c|c|}
\hline Common Names. & Botanical Names. \\
\hline $\begin{array}{l}\text { Panicled Bugloss. } \\
\text { Double White Wilfoil. } \\
\text { Purple Monk's Hood. } \\
\text { Variegated fiowering do. } \\
\text { Japan do. } \\
\text { Rose Campion. } \\
\text { White do. } \\
\text { Double Chinese Hollyhock. } \\
\text { Black do. } \\
\text { Yellow do. } \\
\text { Italian Blue Bugloss. } \\
\text { Yellow Amaryllis. } \\
\text { Silver leaved Alyssum. } \\
\text { Broad leaved Amsonia. } \\
\text { Willow do. do. } \\
\text { European dark purple Columbine. } \\
\text { Glandular Columbine, } \\
\text { Hybrid do. } \\
\text { Scarlet do. } \\
\text { Large Red Snap Dragon. } \\
\text { Carnation flowered do. } \\
\text { Orange Swallowwort. } \\
\text { Red do. } \\
\text { New-England Aster. } \\
\text { Narrow leaved do. } \\
\text { Broad leaved do. } \\
\text { Fox-tail Milk Vetch. } \\
\text { Short podded do. } \\
\text { Grass leaved Anthericum. } \\
\text { Double Wood Anemone. } \\
\text { Pasque flower do. } \\
\text { Pennsylvania do. } \\
\text { Blue Sophora or Baptisia. } \\
\text { White do. } \\
\text { Soapwort Gentian. } \\
\text { Purple Betony. } \\
\text { Prickly Pear, or Indian Fig. } \\
\text { Spring Crocus, various colors. }\end{array}$ & $\begin{array}{l}\text { Anchusa paniculata. } \\
\text { Achillea ptarmica pl. } \\
\text { Aconitum napellus. } \\
\text { variegata. } \\
\text { japonicum. } \\
\text { Agrostemma coronaria. } \\
\text { Althea rosea. } \\
\text { nigra. } \\
\text { Anchusa italica. } \\
\text { Amaryllis lutea. } \\
\text { Asphodeleus luteus. } \\
\text { Alyssum argenteum. } \\
\text { Amsonia latifolia. } \\
\text { Aquilegia atropurpurea. } \\
\text { glandilosa. } \\
\text { hybrida. } \\
\text { Antirrhinum majus. } \\
\text { Asclepias tuberosa. } \\
\text { Aster novæ angliæ. } \\
\text { - linarifolius. } \\
\text { Astragalus alopecuroides. } \\
\text { Anthericum liliago. } \\
\text { Anemone thalictroides, } p l . \\
\text { Baptisia cereula. } \\
\text { Gentiana saponaria. } \\
\text { Cactus opuntia. } \\
\text { Crocus vernis. }\end{array}$ \\
\hline
\end{tabular}


Botanical Names.

Creeping rooted Bellflower

Double white Peach leaved Bellflower.

Carpatian, or Alpine Harebell.

Double Blue do.

Double White do.

Canterbury Bells.

Large Flowering do.

Scarlet or Orange Chelone.

Austrian Purple Clematis.

White flowering Upright do.

Purple flowering do.

Lily of the Valley.

Large Bell-flowered do.

Fine leaved Coreopsis.

Lance leaved do.

Large flowering do.

Palmated do.

Whorled do.

Red Flowering Corydalis.

Fringed Pink.

Chinese do.

Spotted do.

Double Garden do., many varieties.

Siberian Bee Larkspur.

Chinese Blue.

$$
\text { Double do. }
$$

Red Fraxinella.

White do.

Purple Foxglove.

Yellow do.

Large flowering Dragon's Head.

Dentated leaved do.

Purple spiked Epilobium.

Fine Blue Echium.

Azure Blue Eupatorium.

Globe Thistle.

Waved leaved Funkia.

Crown Imperial, (several sorts.)

Wing leaved Francoa.

Purple Gladiolus or Sword Lily.

Parrot Striped do.

Horn poppy.

Scarlet Geum.

Bloody Geranium.

Lancashire Geranium.

Yellow Gaillardia.

Virginian Gonolobus.

Creeping Gypsophyla.

Yellow Rock Rose.

Garden Rocket.

Double White do.

Rose colored Hibiscus.
Campanula rapunculoides.

Campanula persicifolia, $p l$.

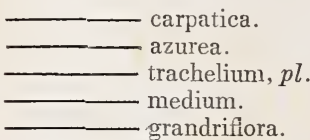

Chelone barbata.

Clematis integifolia.

- erecta.

cerulea.

Convallaria majalis. racemosa.

Coreopsis tenuifolia. lanceolata. grandiflora.

- tripteris. verticillata.

Corydalis formosa.

Dianthus superbus.

- chinense. - guttatus. hortensis.

Delphinium elatum. chinensis.

Dictamnus rubra. pleno.

alba.

Digitalus purpurea. aurea.

Dracocephalum grandiflorum. denticulatum.

Epilobium spicatum.

Echium grandiflorum.

Eupatorium celestinum.

Echinops ritro.

Funkia undulata.

Fritillaria imperialis.

Francoa appendiculata.

Gladiolus communis. pscittascina.

Glauceum luteum.

Geum coccineum, splendens.

Geranium sanguineum. lancastriense.

Galliardia aristata.

Gonolobus discolor.

Gypsophila elegans.

Helianthemum vulgare.

Hesperis matronalis.

- pleno.

Hibiscus palustris. 
Common Names.

White do.

Halbert Leaved.

Yellow day Lily.

Blue Japanese Day-lily.

White Day-lily, superb.

Two-leaved Jeffersonia.

White Florentine Iris.

Chalcedonian do., very singular.

English Yellow do.

Dwarf Crested do.

Siberian Light Blue do.

English Bulbous do.

Perennial Pea.

Large Spiked Liatris, or Blazing Star.

Fine blue Lupin.

Cardinal Flower.

Mexican Lupin.

Large Leaved.

Scarlet Lychnis.

Double Scarlet do.

White Flowering do.

Siberian Brilliant.

Chinese Orange do.

New large Scarlet.

Double Red Ragged Robin.

Yellow Loosestrife.

Creeping do., or Moneywort.

Willow Herb.

Tiger Lily.

English White Lily.

Orange Lily.

Japan White do., splendid.

Yellow Monkey Flower.

Crimson Monarda.

Pale Purple do.

Double White Narcissus, (and many other species.)

Star of Bethlehem.

Pyramidal do.

Frazer's Yellow Primrose.

Yellow Fruticose do.

Large White do.

Dark Purple Orobus.

Early Blue Omphalodes, beautiful.

Oriental Poppy.

Blackberry Lily.

Blue Phy teuma.

Common dbl. Red Pæony.

Chinese dbl. White Pæony, superb, 75 cents.

Chinese dbl. Crimson, large, and splendid flowering, 50 cents.
Botanical Names.

moscheutos.

militaris.

Hemerocallis flava.

Hemerocallis ceruela.

Jeffersonia diphylla

Iris florentina.

- susiana.

- pseudacorus.

- cristata.

- siberica.

— ziphioides.

Lathyrus latifolius.

Liatris spicata.

Lupinus polyphyllus.

Lobelia cardinalis.

Lupinus Mexicanus. grandifolius.

Lychnis chalcedonica.

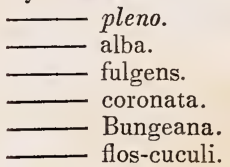

Lysamachia verticillata.

Lythrum salicaria.

Lilium chinense.

- candidum.

- auranticum. - japonica.

Mimulus rivularis.

Monarda didyma.

- oblongata.

Narcissus, $s p$.

Ornithologalum umbellatum.

Oeonothera fraseri. pyramidalus. fruticosa. taraxicifolia.

Orobus nigra.

Omphalodes verna.

Papaver orientale.

Pardanthus chinensis.

Phyteuma campanuloides.

Pæonia officinalis. whitleji. humei. 


\begin{tabular}{|c|c|}
\hline Common Names. & Botanical Names. \\
\hline 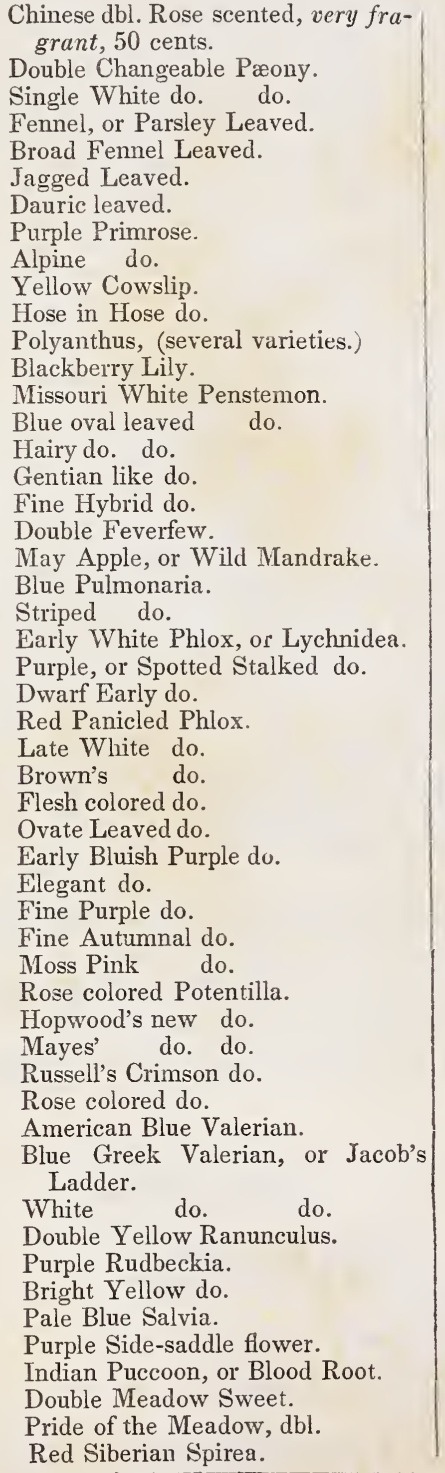 & $\begin{array}{l}\text { fragrans. } \\
\text { albicans, } p l . \\
\text { edulis. } \\
\text { tenuifolia. } \\
\text { latifolia. } \\
\text { anomala. } \\
\text { daurica. } \\
\text { Primula purpurea. } \\
\text { certusoides. } \\
\text { veris. } \\
\text { rubra. } \\
\text { Pardanthus chinensis. } \\
\text { Penstemon digitalis. } \\
\text { ovata. } \\
\text { pubescens. } \\
\text { gentianoides. } \\
\text { hybrida var. } \\
\text { Pyrethrum parthenium, } p l . \\
\text { Podophyllum peltatum. } \\
\text { Pulmonaria virginica. } \\
\text { Phlox suaveolens. } \\
\text { maculata. } \\
\text { verna. } \\
\text { paniculata. } \\
\text { alba. } \\
\text { - lobata. }\end{array}$ \\
\hline
\end{tabular}




\begin{tabular}{|c|c|}
\hline Common Names. & Botanical Names. \\
\hline $\begin{array}{l}\text { New Tufted do. } \\
\text { Japan Spirea. } \\
\text { Thrift, or Sea Pink. } \\
\text { Purple Siberian Saxifrage. } \\
\text { Creeping do. } \\
\text { Poplar Leaved Sedum. } \\
\text { Siebolt's Pink do. } \\
\text { Blue Virginia Spiderwort. } \\
\text { White do. do. } \\
\text { Fragrant Colt's-foot. } \\
\text { Garden Tulips, a variety. } \\
\text { Purple Trillium. } \\
\text { European Globe Flower. } \\
\text { Pyramidal Verbascum. } \\
\text { Purple Phenecian do. } \\
\text { White Valerian. } \\
\text { Virginian Speedwell. } \\
\text { Gentian leaved do. } \\
\text { Blue Spike flowered. } \\
\text { Dwarf do. } \\
\text { Pale blue do. } \\
\text { European fragrant blue Violet. } \\
\text { White do. } \\
\text { Double blue do. } \\
\text { Double white do. } \\
\text { Heart's Ease, or Pansy, (many large } \\
\text { and fine varieties. } \\
\text { Periwinkle or Creeping Myrtle. } \\
\text { Golden Striped do., white flowers. } \\
\text { Adam's Thread or Thready Yucca. } \\
\text { Profuse flowering Yucca. }\end{array}$ & $\begin{array}{l}\text { americana. } \\
\text { Statice Japonica. } \\
\text { Saxifraga crassifolia. } \\
\text { Sedum populifolium. } \\
\text { Tradescantia virginica. } \\
\text { Tussillago fragrans. } \\
\text { Tulipa gesneriana. } \\
\text { Trillium erectum. } \\
\text { Trollius europeus. } \\
\text { Verbascum pyramidalis. } \\
\text { Valeriana officinalis. } \\
\text { Veronica virginica. } \\
\text { gentianoides. } \\
\text { spicata. } \\
\text { pumila. } \\
\text { Viola odorata. } \\
\text { alba. } \\
\text { purpurea, pl. } \\
\text { alba, pl. } \\
\text { Vinca major. } \\
\text { Yucca filamento }\end{array}$ \\
\hline
\end{tabular}

The following bulbous and herbaceous plants are too tender to withstand our winters without some protection. The bulbs may be taken up and kept in a dry warm cellar, and the herbaceous plants in small pots in the parlor, or green-house. The Petunias and Verbenas turned out in the borders in spring, make a brilliant display of blossoms during the whole floral season.

\begin{tabular}{|c|c|}
\hline Common Names. & Botanical Names. \\
\hline $\begin{array}{l}\text { Jacobean Amaryllis. } \\
\text { Superb striped do. } \\
\text { Madeira Vine, fragrant white } \\
\text { flowers. } \\
\text { Climbing Cobea, a rapid growing } \\
\text { vine. } \\
\text { Purple Maurandia, a beautiful } \\
\text { climber. }\end{array}$ & $\begin{array}{l}\text { Amaryllis formossisima. } \\
\text { Basella tuberosa. } \\
\text { Cobea scandens. } \\
\text { Maurandia Barclayana. }\end{array}$ \\
\hline
\end{tabular}




\begin{tabular}{|c|c|}
\hline Common Names. & Botanical Names. \\
\hline $\begin{array}{l}\text { Red flowering do. (or Lophosper- } \\
\text { mum,) pretty climber. } \\
\text { Purple Petunia. } \\
\text { Groom's new dark purple. } \\
\text { Large White and Lilac. } \\
\text { Striped Pink and purple. } \\
\text { New White Penciled. } \\
\text { Double Tuberose. } \\
\text { Mexican Scarlet Sage. } \\
\text { Crimson Fulgent do. } \\
\text { Superb blue do. } \\
\text { Mexican Tiger flower. } \\
\text { Orange or Shell flowered do. } \\
\text { Scarlet Trailing Verbena. } \\
\text { Tweed's Crimson do. } \\
\text { Brill's Early Pink do. } \\
\text { Brill's large Pink do. } \\
\text { Large shaded. } \\
\text { White Fragrant do. } \\
\text { Chalmers' new white do. } \\
\text { New, fine blush do. } \\
\text { Elegant pink flowering do. } \\
\text { Binney's fine purple do. } \\
\text { Wilson's scarlet do. } \\
\text { Queen pure white, fine. } \\
\text { Royal purple. } \\
\text { Alba floritunda. } \\
\text { Cylinder scarlet. } \\
\text { Rosy Zephyranthes. }\end{array}$ & 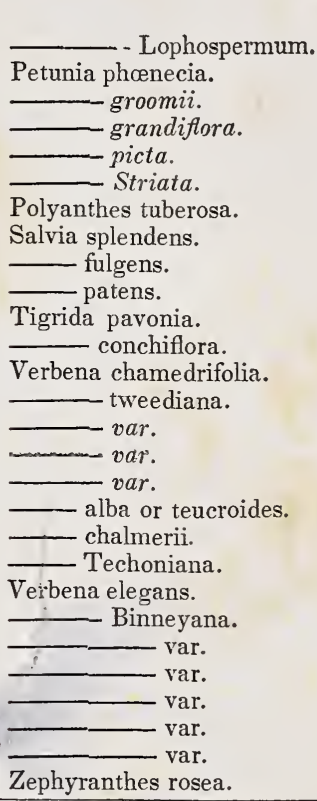 \\
\hline \multicolumn{2}{|c|}{ DoUble $D_{A H L I A S}$ of many varieties. } \\
\hline
\end{tabular}


